\title{
A Method for the In-Situ Study of Solid-State Joining Techniques using Synchrotron Radiation - Observation of Phase Transformations in Ti-6Al-4V after Friction Surfacing
}

\author{
S. Hanke ${ }^{\mathrm{a} 1}$, P. Staron ${ }^{\mathrm{b}}$, T. Fischer ${ }^{\mathrm{b}}$, V. Fitseva ${ }^{\mathrm{a}}$, J.F. dos Santos ${ }^{\mathrm{a}}$ \\ ${ }^{a}$ Helmholtz-Zentrum Geesthacht, Institute of Materials Research, Materials Mechanics, Solid \\ State Joining Processes, Max-Planck-Straße 1, 21502 Geesthacht, Germany \\ ${ }^{b}$ Helmholtz-Zentrum Geesthacht, Institute of Materials Research, Materials Physics, X-ray \\ Diffraction with Synchrotron Radiation, Max-Planck-Straße 1, 21502 Geesthacht, Germany
}

\begin{abstract}
The solid-state deposition process Friction Surfacing (FS) was applied to Ti-6Al-4V alloy on portable welding equipment at a high-energy synchrotron beamline. The heat input and coating thickness were altered by varying the deposition speed. X-ray diffraction was carried out insitu during the deposition process and the cooling of the coated samples. Phase transformations were evaluated and correlated with thermal cycles determined by thermocouples and an infrared camera. SEM investigation of the coating microstructure was conducted to examine the morphology of the $\alpha$ phase. During FS the coating material is severely deformed and dynamically recrystallized in the $\beta$ phase state at temperatures $>1300^{\circ} \mathrm{C}$. Small changes in the $\beta$ grain size were observed within the first $2 \mathrm{~s}$ after deposition only. Depending on the cooling rate it transforms into different types of $\alpha$ phase during cooling. Phase transformation rates were found to correlate well with the differences in $\alpha$ morphology. The two faster translational speeds showed transformation rates $>45 \mathrm{vol} \% / \mathrm{s}$ and a partially martensitic microstructure.
\end{abstract}

${ }^{1}$ Corresponding author. Permanent address: University Duisburg-Essen, Materials Science and Engineering, Lotharstr. 1, 47057 Duisburg, Germany, tel.: +49 203379 1269; fax: +49 203379 4374; stefanie.hanke@uni-due.de 
When a thick coating is deposited at low translational speed, $\alpha \rightarrow \beta$ transformation continues for several seconds after deposition, followed by a slow cooling rate resulting in martensite free coatings containing $\alpha_{\mathrm{m}}$ from massive transformation. The potential gain and the deficiencies of this complex in-situ study of a technical process, instead of simplified model experiments, for the understanding of fundamental mechanisms involved in FS are discussed.

Keywords: friction surfacing, phase transformations, Ti-alloys, synchrotron, microstructure, severe plastic deformation 


\section{Introduction}

The Friction Surfacing (FS) process is used to deposit mainly metallic materials in solid state. The coating material is brought into a "plastified" state of low shear strength at high temperatures through plastic deformation under an applied pressure, and can then form a metallurgical bond to the substrate. The source material to form the coating is initially a solid stud rotating around its longitudinal axis. Its face is brought into contact with the substrate surface under a defined axial force. Immediate frictional heating causes the stud material to adhere to the substrate and torsional shear deformation sets in. Heat generation occurs through plastic deformation within the stud, the rotational relative motion now being accommodated by shearing of a narrow stud material volume [1]. When an additional translational movement of the stud parallel to the substrate surface is introduced, part of the thermally softened, plastified material is deposited behind the stud and forms a coating layer. Another fraction of the plastified material is squeezed out from the stud tip in radial direction and forms a flash. Both the material fraction going into the flash as well as the obtained coating geometry can vary. The most significant influencing factors are the materials used [2], the rotational and translational speed as well as axial force [3] and optional cooling measures [4]. FS is of interest a.o. for repair welding of cast alloys causing problems under fusion welding [5], for local strengthening through increase in cross section or as buffer layers for joints from dissimilar material combinations, because minimal dilution with the substrate can be achieved [3]. Further, it may be used for generating advantageous microstructural states with regard to homogeneity and non-equilibrium phases through the thermomechanical processing involved [6].

Ti-6Al-4V is a common alloy with an advantageous strength-to-weight ratio, which leads to its use e.g. in airplane landing gear or as turbine blades in spite of its high cost [7]. The feasibility of processing Ti-6Al-4V by FS was recently reported by Fitseva et al. [8]. The flow stress of Ti-alloys varies in a complex way with changes in temperature and strain rate, as they occur during plastification in FS. This results in process instabilities, particularly in fluctuations in 
axial force. Therefore, the typically applied axial force control during the deposition process was replaced with controlling the speed at which the stud is fed into the process (consumption rate control mode), which allows a stable FS process for Ti-alloys [8]. Ti-alloys are sensitive to changes in the microstructure, particularly regarding cyclic mechanical properties [7]. Controlling the resulting microstructure is therefore of great importance when processing Tialloys.

Homogeneous fine-grained microstructures can be achieved by FS, yielding excellent mechanical properties of the coatings. Microstructures in FS coatings have been investigated for various materials, including Cr-based [9], Ni-based [10] and Ti-based alloys [11]. Materials containing several phases or having a temperature dependent allotropy undergo phase transformations during heating, enhanced by the energy input through the introduced strain. Cooling rates after deposition are high, due to the low heat input and the fast conduction into the backing and the clamping fixtures. This can lead to the formation of non-equilibrium phases, e.g. martensite in some steels [12] or Ti-6Al-4V [8], or the suppression of re-precipitation of dissolved secondary phases, resulting in supersaturated solid solution, e.g. in Cr60Ni40 [9]. The dynamically recrystallizing grain size present during processing (and possible grain growth during cooling) affects the final microstructure, and can in some materials be controlled by the selection of suitable process parameters. For Ti-6Al-4V it was shown that the high temperature $\beta$ grain size can be varied from 1 to $30 \mu \mathrm{m}$ by applying rotational speeds from 600 to $6000 \mathrm{~min}^{-}$ ${ }^{1}$. The grain size increases with rising rotational speeds and process temperatures [11]. Further details on the effects of process parameter variations on FS coating properties are described in [8] and [11].

Literature on recrystallization mechanisms and material properties under the particular conditions the materials encounter during FS is scarce. Without a deeper understanding of the material behaviour under severe plastic deformation at very high temperatures and strains the 
necessary information to control the resulting microstructure can only be gained from extensive experimental studies, and no theoretical prediction is possible [13] [14] [15].

In order to gain a better understanding of the metallurgical processes through in-situ measurements, in the present work FS of Ti-6Al-4V on self-mating substrate was conducted on portable welding equipment at the German synchrotron facility DESY (Deutsches Elektronen Synchrotron, Hamburg, Germany).

The aim of this work is to establish the feasibility and clarify the potential of in-situ synchrotron measurements on a solid-state joining process. This first experiment applying high-energy Xray diffraction on a running FS process shows which information can be obtained from such an approach, and also which deficiencies must be overcome in future experiments. It was not possible to achieve sufficient intensity contrast directly within the process zone in the set-up chosen, because in this position the beam passes through a large material volume including the flash or even the stud. During cooling after deposition successful measurements were accomplished. High temperature $\beta$ grain growth, the rate of phase transformations and the corresponding microstructure can be correlated and related to the process parameters.

\section{Experimental Methods}

\subsection{Experimental Set-up for In-Situ Measurements during Friction Surfacing}

\subsubsection{Friction Surfacing Equipment}

Portable welding equipment (Fig. 1) was used which enables FS at a synchrotron beamline. The equipment was designed and built according to specification from Helmholtz-Zentrum Geesthacht (HZG) by H. Loitz - Robotik, Hamburg, Germany, and is suitable for Friction Stir Welding (FSW) and FS, within certain load limitations. The main components are an electrically driven spindle by which the rotational movement of the studs was realized, and a slotted linear table to clamp the substrate and carry out all translational movements. The 
equipment allows to monitor the torque acting on the spindle, the position of the stud in its axial direction ( $\mathrm{z}$ axis), the position of the table in two lateral directions ( $\mathrm{x}$ and $\mathrm{y}$ axes) as well as the forces acting in all these directions.

The particular feature of the equipment, which allows for the in-situ measurements, is the fact that it can be tilted to an angle of up to $60^{\circ}$. Further, the slotted table contains a $40 \mathrm{~mm}$ wide slit parallel to the translational deposition direction. The whole design allows the synchrotron beam to pass through the equipment without any interference, except for the sample clamped on the table. With the detector placed behind the equipment, measurements in transmission during the running process are possible. Fig. 1 shows the equipment set up in the experimental hut with a tilt angle of $56^{\circ}$, and the detector visible behind the machine.

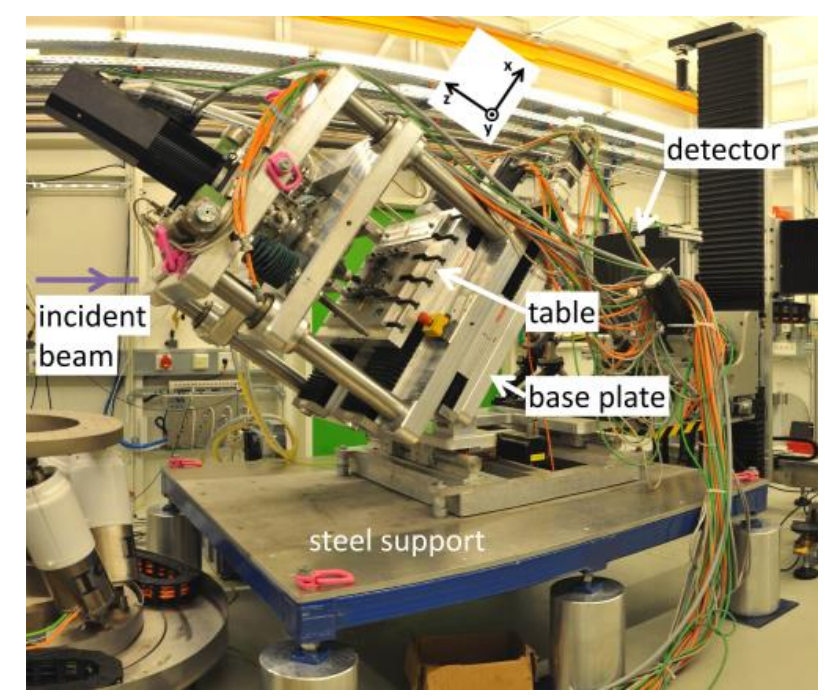

Fig. 1: Portable friction welding equipment set-up at the synchrotron facility DESY.

The equipment's base plate has two linear drives which allow precise positioning relative to the synchrotron beam. Together with the linear drive of the slotted table, which carries out the FS translational movement, the whole equipment can be moved during the running process in such a manner that the beam incident spot remains in a position fixed on the moving sheet, if desired. In the current study the sheet with the deposited material moved underneath the beam incident spot with the selected FS translational speed. 


\subsubsection{Temperature Measurements}

Temperature measurements were conducted during separate experiments with the same process parameters and the same equipment used for the in-situ diffraction experiment. Two methods were applied.

Thermocouples were used to determine the temperature in the interface between the coating and the substrate by drilling $\varnothing 1 \mathrm{~mm}$ holes through the substrate sheets and the $\mathrm{Cu}$ backing plate. Thermocouples were inserted from the back through both sheets and fixed with the tip at the height of the Ti-6Al-4V sheet surface, in the middle of the width of the coating to be deposited. The local increase in temperature when the stud crosses as well as the cooling after deposition were recorded with an acquisition rate of $50 \mathrm{~Hz}$.

Further, an infrared camera (ImageIR 8300, Infra Tec GmbH, Dresden, Germany) was employed to observe the process from the outside. The camera was placed beside the equipment, with the direction of view perpendicular to the transverse speed direction. It was positioned so that the substrate surface was in the centre of the image and oriented parallel to the direction of view. The camera filter was set to a range of 650 to $1300^{\circ} \mathrm{C}$, the latter being the upper limit of the device. Data was recorded at $80 \mathrm{~Hz}$ throughout the process and during cooling. Emission factors were determined using controlled heating of FS coatings in an oven [11] and applied to the measured data.

\subsubsection{Friction Surfacing Procedure}

The FS process itself starts with the stud, rotating at the set speed, touching the substrate under a set axial force. The stud immediately plastifies, a thin volume of the stud tip displaying a radiant heat colour within the first second under load. The axial movement of the softening stud is monitored by the equipment, and when $0.2 \mathrm{~mm}$ of stud length is consumed the deposition process is initiated. Now the translational movement sets in and a constant axial velocity is applied (consumption rate control), feeding the stud into the process zone at $1.8 \mathrm{mms}^{-1}$. 
Deposition layers of $115 \mathrm{~mm}$ length were produced. When this length was reached the translational movement stopped and the stud was lifted off the sheet. The equipment remained in this state and the deposit cooled down in air until the diffraction measurements were finished. No protective gas was used in order to simplify the in-situ set-up. No differences in process behaviour and microstructure were observed compared to previous welds with Ar protective gas [8], [11].

Preliminary trials showed that heat accumulation occurred in the substrate above the slit in the machine table, resulting in heavy thermal softening and deformation of the sheets. To avoid this, a backing plate from commercially pure $\mathrm{Cu}$ was placed underneath the Ti-6Al-4V sheet. This $\mathrm{Cu}$ sheet ensured heat conduction away from the surfacing region, and the Ti-6Al-4V sheet retained sufficient strength to avoid severe deformation under the process load. The diffraction peaks obtained from the $\mathrm{Cu}$ do not overlap with the Ti peaks in the diffraction data.

Wrought studs with a diameter of $20 \mathrm{~mm}$ and a length of $120 \mathrm{~mm}$ and for the substrate rolled sheets of $2 \mathrm{~mm}$ thickness were used. The surfaces were degreased with ethanol. The chemical composition of sheets and studs according to the manufacturer's certificate is given in Tab. 1 . The main process parameters for the current study are summarized in Tab. 2 .

\begin{tabular}{lllllllll}
\hline & $\mathrm{Fe}$ & $\mathrm{C}$ & $\mathrm{N}$ & $\mathrm{H}$ & $\mathrm{O}$ & $\mathrm{Al}$ & $\mathrm{V}$ & $\mathrm{Ti}$ \\
\hline sheets & 0.11 & 0.02 & 0.007 & 0.0049 & 0.049 & 6.2 & 3.9 & bal. \\
\hline studs & 0.11 & 0.03 & 0.023 & 0.0039 & 0.15 & 6.6 & 3.5 & bal. \\
\hline
\end{tabular}

Tab. 1: Chemical composition of Ti-6Al-4V sheet and stud material.

\begin{tabular}{l|ll}
\hline rotational speed $\mathrm{v}_{\mathrm{n}}$ & $3000 \mathrm{~min}^{-1}$ & \\
\hline translational speed $\mathrm{v}_{\mathrm{x}}$ & $8 \mathrm{mms}^{-1}$ & $16 \mathrm{mms}^{-1}$ \\
\hline stud consumption rate $\mathrm{v}_{\mathrm{CR}}$ & $1.8 \mathrm{mms}^{-1}$ & \\
\hline deposition length 1 & $115 \mathrm{~mm}$ & \\
\hline stud material & Ti-6Al-4V & $\emptyset 20 \mathrm{~mm}$ \\
\hline substrate material & Ti-6Al-4V & $300 \mathrm{~mm} \times 100 \mathrm{~mm} \times 2 \mathrm{~mm}$ \\
\hline
\end{tabular}




\begin{tabular}{l|ll}
\hline backing plate & $\mathrm{CPCu}$ & $300 \mathrm{~mm} \times 100 \mathrm{~mm} \times 2 \mathrm{~mm}$ \\
\hline
\end{tabular}

Tab. 2: Main FS process parameters and materials.

\subsubsection{Synchrotron Measurements}

The synchrotron diffraction experiments were carried out at the High-Energy Materials Science beamline HEMS (P07) of HZG, located at the synchrotron source PETRA III of DESY. A series of diffraction images were recorded for each FS process run using a Perkin Elmer flat panel area detector with $200 \mu \mathrm{m}$ pixel size. Based on the thickness and absorption properties of the investigated materials, i.e. $2 \mathrm{~mm}$ Ti- $6 \mathrm{Al}-4 \mathrm{~V}$ sheet, $2 \mathrm{~mm} \mathrm{Cu}$ sheet and deposited coating material of 0.8 to $2.3 \mathrm{~mm}$ thickness, penetrated at an angle of $56^{\circ}$, a compromise between measurement rate, gauge volume and achieved intensity was made for the desired in-situ study. An X-ray beam cross-section of $1 \mathrm{~mm} \times 1 \mathrm{~mm}$ and an exposure time of $0.2 \mathrm{~s}$, which together with data processing dead time resulted in an acquisition rate of $\approx 3.3 \mathrm{~Hz}$, were found to be satisfactory. The photon energy was set to $98.5 \mathrm{keV}$, corresponding to a wavelength of $0.1259 \AA$ A The distance between the measurement location, i.e. the coated sheet, and the detector was $1765.5 \mathrm{~mm}$, verified through calibration using $\mathrm{CeO}_{2}$ powder (see section 2.2).

Each measurement run can be divided into two stages. The synchrotron measurement was triggered during the running process when the stud reached a position corresponding to half the deposition length. The measurement position of the beam was set at a distance of $17.5 \mathrm{~mm}$ behind the stud centre, while the sheet traversed underneath the stud. The distance of $17.5 \mathrm{~mm}$ was required to avoid the beam passing through the flash. A schematic depiction of the measurement configuration is shown in Fig. 2. The time for a specific material volume between its deposition and the incident of the beam, after traversing of the stud by $17.5 \mathrm{~mm}$, varies for the different translational speeds. The material moving through the gauge volume for a certain translational speed is always in the same state of cooling in this measurement stage 1. 
When the stud reached its predefined end position it was lifted off the sheet and the translational movement of the sheet stopped. The diffraction measurement continued at the last position of the incident beam during the running process; i.e. at $17.5 \mathrm{~mm}$ distance to the stud's final position. In this measurement stage 2, a fixed material volume was examined as it cooled down. FS process related characteristics of the diffraction measurements are summarized in Tab. 3 .

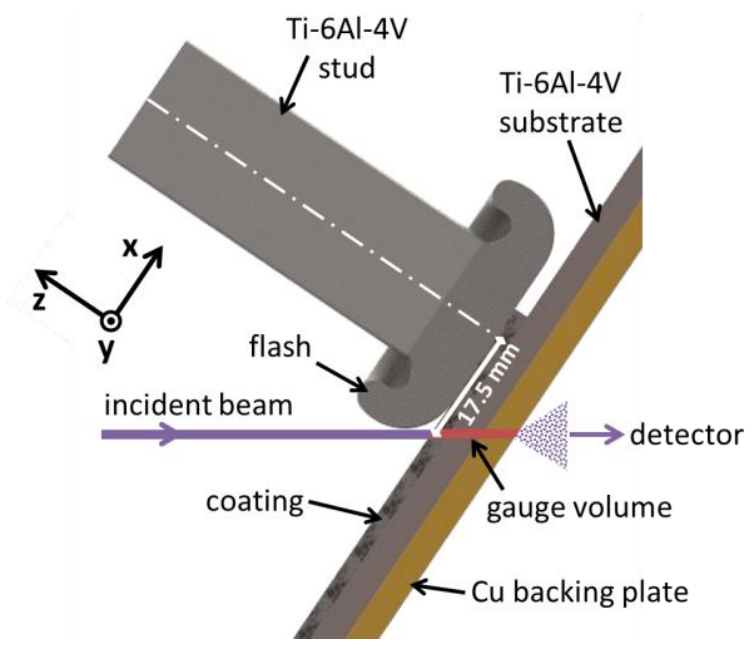

Fig. 2: Schematic of the synchrotron measurement configuration.

\begin{tabular}{l|lcc}
\hline translational speed & $8 \mathrm{mms}^{-1}$ & $16 \mathrm{mms}^{-1}$ & $24 \mathrm{mms}^{-1}$ \\
\hline $\begin{array}{l}\text { time between deposition and measurement of a discrete } \\
\text { material volume in stage } 1\end{array}$ & $2.2 \mathrm{~s}$ & $1.1 \mathrm{~s}$ & $0.7 \mathrm{~s}$ \\
\hline traversed distance during $0.2 \mathrm{~s}$ exposure time in stage 1 & $1.6 \mathrm{~mm}$ & $3.2 \mathrm{~mm}$ & $4.8 \mathrm{~mm}$ \\
\hline $\begin{array}{l}\text { gauge volume of fixed material volume in stage } 2 \\
\text { (coating } \approx 1 \mathrm{~mm}, \mathrm{Cu} \text { and Ti-6Al-4V sheet } 2 \mathrm{~mm} \text { each) }\end{array}$ & $\approx 6 \mathrm{~mm}^{3}$ & & \\
\hline
\end{tabular}

Tab. 3: Characteristic values for the X-ray diffraction measurements during FS.

\subsection{Analysis of Diffraction Data}

Detector images were processed using FIT2D [16]. Azimuthal integration was carried out to obtain one-dimensional diffraction patterns. $\mathrm{CeO}_{2}$ powder was measured to determine the detector distance and the detector tilt. 
A Rietveld refinement for an analysis of the phase content was done with the software Maud by Luca Lutterotti [17]. The Ti $\alpha$-phase with the symmetry P63/mmc and lattice parameters $a$ $=2.91 \AA$ and $c=4.658 \AA$ and the Ti $\beta$-phase with the symmetry $\operatorname{Im} 3 \mathrm{~m}$ and a lattice parameter $a=3.246 \AA$ were used for fitting [18]. A Cu phase was added for the backing sheet (symmetry Fm-3m, lattice parameter $3.651 \AA$ ).

\subsection{Microstructure Investigations}

For microstructure investigations, metallographic cross sections were prepared by standard methods. Samples were taken from the base material and from coated substrates with the observed plane perpendicular to the deposition direction. Mechanical grinding and polishing down to $0.1 \mu \mathrm{m}$ particle size Silica suspension was applied. Samples were etched using Kroll's agent (96\% $\mathrm{H}_{2} \mathrm{O}$ dest., $2 \%$ nitric acid, $2 \%$ fluoric acid). Scanning-electron microscopy (SEM) was employed to study the morphology of the phases (Quanta FEG 650, FEI Europe B.V., Eindhoven, The Netherlands) and local chemical composition was measured by energy dispersive X-ray spectroscopy (EDS: Apollo X-SDD, EDAX Inc., Mahwah, NJ, USA).

\section{Results}

\subsection{Friction Surfacing Process and Coating Characteristics}

The superposition of rotational and translational movement during FS causes a characteristic asymmetry of the process. On the retreating side (RS) of the deposited layer, the stud rotation is oriented opposite to the translational movement direction. Along the other edge the two motions act in the same direction, and their velocities add up. This side is denominated the advancing side (AS). In Fig. 3, the typical appearance of a Ti-6Al-4V FS coating is presented. 


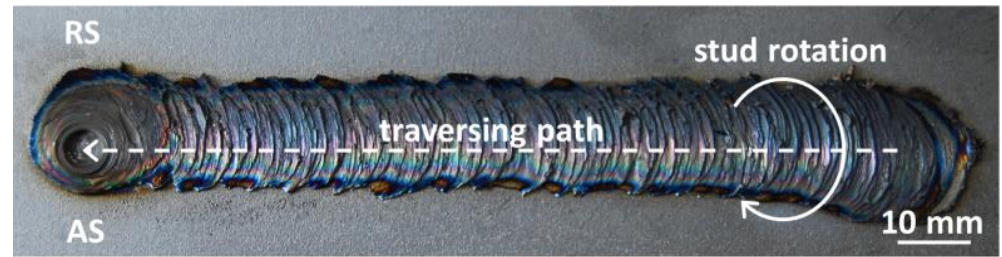

Fig. 3: Top view of a Ti-6Al-4V coating, deposited at $v_{n}=3000 \mathrm{~min}^{-1}$ and $v_{x}=24 \mathrm{mms}^{-1}$. AS: advancing side, RS: retreating side.

Metallographic cross sections perpendicular to the welding direction at half the coating length, from three coatings produced at different translational speeds, are presented in Fig. 4. At the lowest translational speed deformation of the substrate is obvious, due to the longer exposure time of the sheet material to pressure and temperatures (Fig. 4 (a)). This coating has a significantly higher thickness $(\approx 2.3 \mathrm{~mm})$ compared to the other two $(\approx 0.6$ to $0.8 \mathrm{~mm})$. The heat-affected zones (HAZ) can be distinguished, since they etch differently than the unaffected substrate. For the low translational speed the HAZ includes the full sheet thickness and the boundaries of the HAZ are visible as bright lines underneath the two coating edges (Fig. 4 (a)). The HAZ of the intermediate translational speed reaches up to $1.5 \mathrm{~mm}$, and the one of the fastest deposition approximately $1.0 \mathrm{~mm}$ deep into the sheet material.
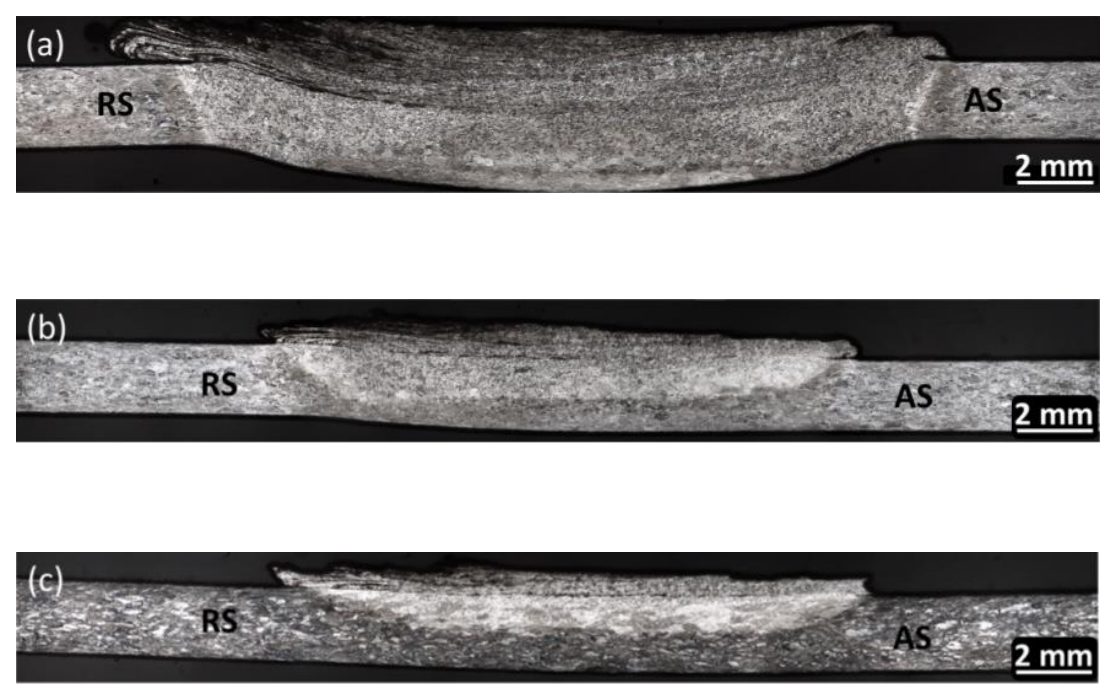

Fig. 4: Metallographic cross sections perpendicular to welding direction. FS coatings deposited at $\mathrm{v}_{\mathrm{x}}=8 \mathrm{mms}^{-1}(\mathrm{a}), \mathrm{v}_{\mathrm{x}}=16 \mathrm{mms}^{-1}(\mathrm{~b})$ and $\mathrm{v}_{\mathrm{x}}=24 \mathrm{mms}^{-1}$ (c). 


\subsection{Process Temperatures}

Temperature cycles recorded by thermocouples in the interface between the substrate and deposited coatings at a distance of $40 \mathrm{~mm}$ from the process start point are presented in Fig. 5 . All thermal cycles depict the stud passing over the measurement position and the following cooling of the deposited layer. The rise from room $\left(23^{\circ} \mathrm{C}\right)$ to maximum temperature occurs rapidly within 1.3 to $3.6 \mathrm{~s}$. The interface peak temperatures range between 987 and $1254^{\circ} \mathrm{C}$, lower translational speeds resulting in higher peak temperatures. These findings correlate well with results previously obtained using different welding equipment and sheet thickness of $10 \mathrm{~mm}$ [8]. After deposition the temperature initially drops fast and the cooling rates reduce with decreasing temperature. For the curves presented in Fig. 5 the cooling rates from peak down to $600^{\circ} \mathrm{C}$ and from there to $400^{\circ} \mathrm{C}$ are the following: $80 \mathrm{Ks}^{-1}$ and $26 \mathrm{Ks}^{-1}\left(8 \mathrm{mms}^{-1}\right), 160$ $\mathrm{Ks}^{-1}$ and $77 \mathrm{Ks}^{-1}\left(16 \mathrm{mms}^{-1}\right)$ and $101 \mathrm{Ks}^{-1}$ and $61 \mathrm{Ks}^{-1}\left(24 \mathrm{mms}^{-1}\right)$, respectively. Further measurements revealed scattering of the obtained cooling rates ranging within the given values, and with a tendency to lower cooling rates for lower translational speeds. The observation of "kinks" in the temperature curves as seen in Fig. 5 between 700 and $800^{\circ} \mathrm{C}$ has been described before [11] and was considered to be due to a martensitic phase transformation. Since martensite start temperatures given in the literature vary, and considering the high cooling rates which may lead to undercooling, the kinks might also be related to different $\beta \rightarrow \alpha$ transformation processes (see sections 3.4.3 and 4.2). The temperature curves of $8 \mathrm{mms}^{-1}$ depositions display an additional kink at $\approx 1100^{\circ} \mathrm{C}$ which will be further discussed in section 4.2.2. The grey arrows in the diagrams in Fig. 5 mark the onset of the synchrotron measurements, as described in section 2.1.4. The temperatures estimated from the curves to prevail at this instant are $\approx 940^{\circ} \mathrm{C}$ $\left(\mathrm{v}_{\mathrm{x}}=8 \mathrm{mms}^{-1}\right), \approx 840^{\circ} \mathrm{C}\left(\mathrm{v}_{\mathrm{x}}=16 \mathrm{mms}^{-1}\right)$ and $\approx 850^{\circ} \mathrm{C}\left(\mathrm{v}_{\mathrm{x}}=24 \mathrm{mms}^{-1}\right)$. 


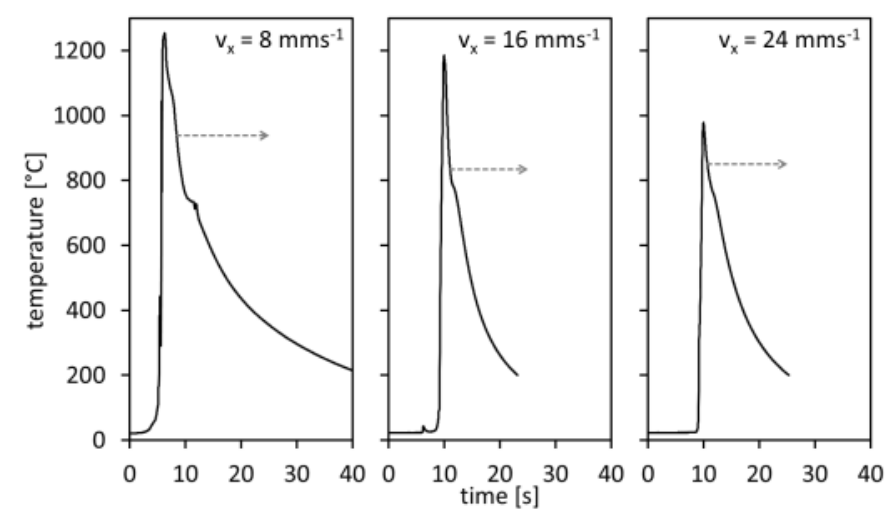

Fig. 5: Thermal cycle in interface between substrate and deposits generated at $\mathrm{v}_{\mathrm{n}}=3000 \mathrm{~min}^{-1}$. The arrows mark the time of onset of the X-ray measurements.

In Fig. 6 a thermogram recorded by the infrared camera at a translational speed of $8 \mathrm{mms}^{-1}$ is presented. The lower part of the flash and the process zone below are depicted in white, indicating temperatures above $1300^{\circ} \mathrm{C}$. The liquidus temperature of Ti-6Al-4V lies at approximately $1600^{\circ} \mathrm{C}$ [19]. The stud, which is invisible here since its temperature is below $650^{\circ} \mathrm{C}$, is schematically indicated in the figure. The measurement position at $17.5 \mathrm{~mm}$ distance from the stud centre, where the synchrotron beam penetrated the sample, is also marked. The temperature on the coating surface in this location is $912^{\circ} \mathrm{C}$, which correlates well with the interface temperature obtained by thermocouples $\left(\approx 940^{\circ} \mathrm{C}\right) .5 \mathrm{~mm}$ further away from the stud centre, at $22.5 \mathrm{~mm}$ distance, the temperature is $801^{\circ} \mathrm{C}$, and at $27.5 \mathrm{~mm}$ distance it is $749^{\circ} \mathrm{C}$. At the translational speed of $8 \mathrm{mms}^{-1}$ the coated substrate needs $1.25 \mathrm{~s}$ to pass from the location of the first impinging of the synchrotron beam to the spot at $27.5 \mathrm{~mm}$, which results in a very high initial cooling rate of $130 \mathrm{Ks}^{-1}$. Temperatures exceeding $1300^{\circ} \mathrm{C}$ close to the process zone were observed for all process parameters. Since the $\beta$-transus temperature of Ti-6Al-4V is around $995^{\circ} \mathrm{C}$ [20], the coating material can be assumed to be deposited in $\beta$ state. To observe the cooling of the coating is only possible when generating a coating of high thickness. For faster translational speeds than $8 \mathrm{mms}^{-1}$ either the coatings are too thin to be observed from the lateral direction of view, or their surface temperature drops below $650^{\circ} \mathrm{C}$ extremely fast. 


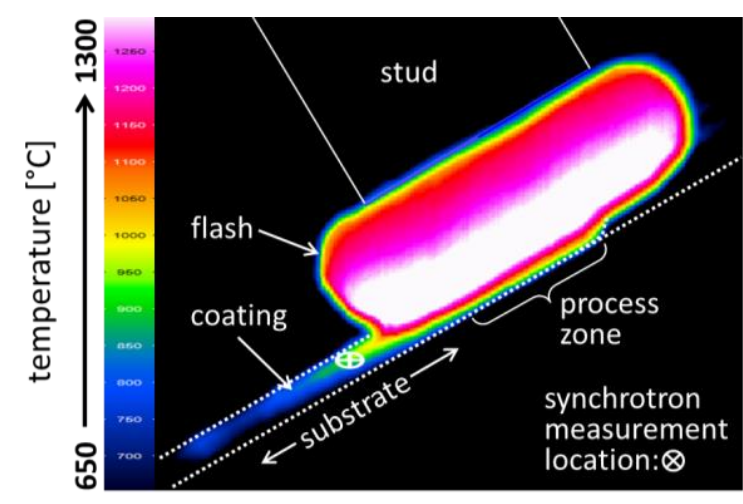

Fig. 6. Infrared thermogram of FS process at $\mathrm{v}_{\mathrm{x}}=8 \mathrm{mms}^{-1}$, displaying flash and deposited material at elevated temperatures according to the colour scale between 650 and $1300^{\circ} \mathrm{C}$. The colder stud, the deposited coating and the measurement location of the synchrotron beam are indicated schematically.

\subsection{Microstructure}

The microstructure of the as-delivered Ti-6Al-4V sheets is presented in the SEM image of an etched through-thickness cross section in Fig. 7 (a). Typical lamellar phase morphology is visible, with thin $\beta$ plates (brighter) and a curved strip of grain boundary $\alpha\left(\alpha_{\mathrm{GB}}\right)$ on the right half of the image. In Fig. 7 (b) the microstructure of the HAZ directly below a deposited FS coating shows that the $\beta$ phase plates in the substrate have disappeared and a homogeneous, acicular $\alpha$ morphology is visible.
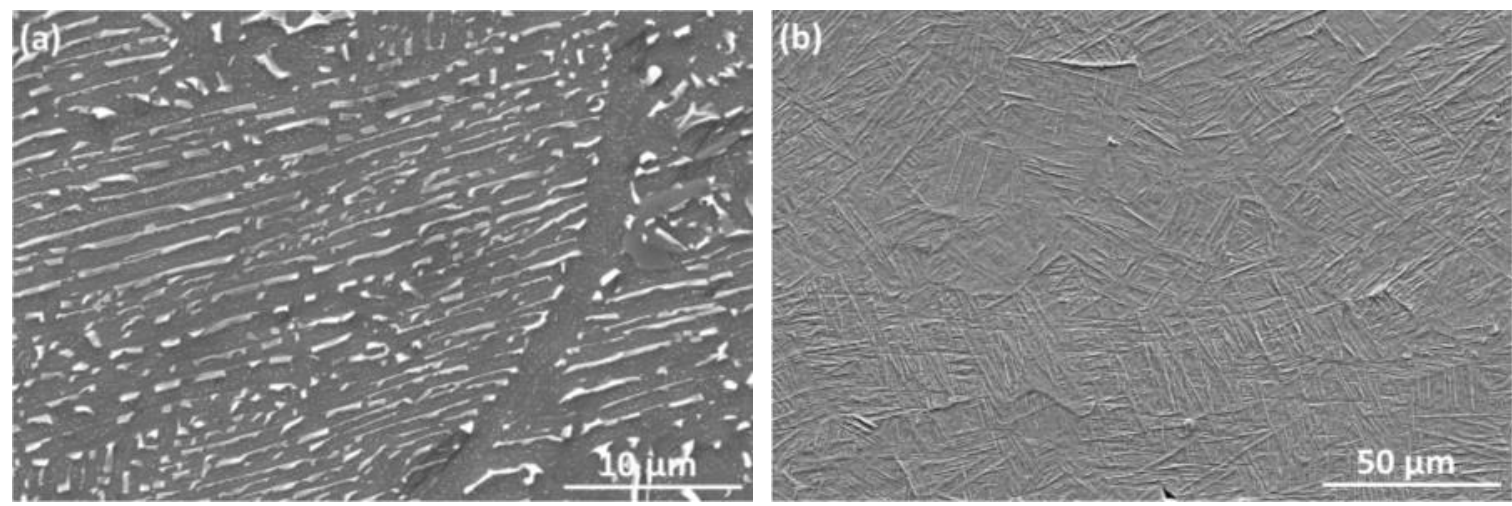

Fig. 7: Microstructure of Ti-6Al-4V substrate sheet in as-delivered state, $\beta$ phase appearing bright (a) and in HAZ below a coating deposited at $\mathrm{v}_{\mathrm{x}}=24 \mathrm{mms}^{-1}$ (b). 
Fig. 8 to Fig. 11 present SEM micrographs of cross sections from deposits generated during the synchrotron measurements. SEM images representative of the respective microstructure were taken at various locations within the coatings. All deposits show a lamellar or acicular microstructure, as expected for $\beta$-processed Ti-6Al-4V, and prior $\beta$ grain boundaries (GB) are visible after etching (Fig. 8). The thick coating generated at $8 \mathrm{mms}^{-1}$ translational speed, with a low cooling rate, shows mainly a basket-weave type of short Widmannstätten $\alpha$ lamellae $\left(\alpha_{\mathrm{W}}\right)$ of various orientations, grain boundary $\alpha\left(\alpha_{\mathrm{GB}}\right)$ and local colonies of thick parallel $\alpha$ lamellae $\left(\alpha_{m}\right)$ resulting from massive transformation (Fig. 8 (a)). The coating deposited at $16 \mathrm{mms}^{-1}$ presented in Fig. 8 (b) shows mainly a martensitic type of $\alpha\left(\alpha^{\prime}\right) . \alpha_{\mathrm{GB}}$ and regions of $\alpha_{\mathrm{W}}$ are visible (Fig. 8 (b)). In the coating generated at $24 \mathrm{mms}^{-1}$ the same combination of $\alpha^{\prime}, \alpha_{\mathrm{GB}}$ and $\alpha_{\mathrm{W}}$ is present (Fig. 8 (c)). An equiaxed type of $\alpha$ grains $\left(\alpha_{\mathrm{p}}\right)$ can be seen in Fig. 8 (c).
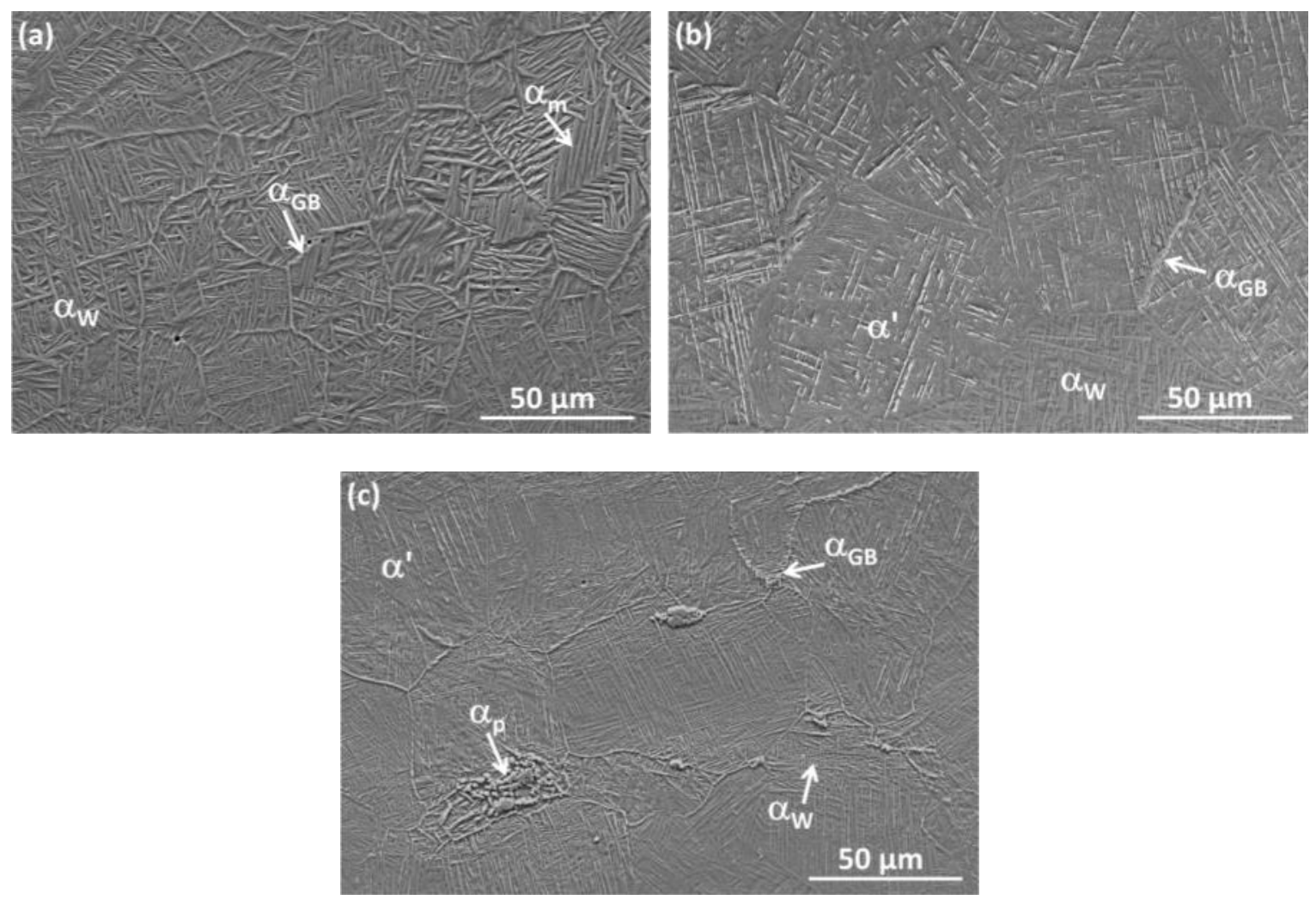

Fig. 8: Microstructure of Ti-6Al-4V deposits generated at $\mathrm{v}_{\mathrm{x}}=8 \mathrm{mms}^{-1}(\mathrm{a}), \mathrm{v}_{\mathrm{x}}=16 \mathrm{mms}^{-1}$ (b) and $\mathrm{v}_{\mathrm{x}}=24 \mathrm{mms}^{-1}(\mathrm{c})$. 
In Fig. 9 details of the microstructure of the three coatings at higher magnification are presented. For the low translational speed, thin plates of $\beta$ phase are visible between $\alpha_{\mathrm{m}}$ lamellae (see arrows in inlay of Fig. 9 (a)), which is not observed for the faster translational speeds. Between $\alpha_{\mathrm{w}}$ only locally $\beta$ was visible by SEM, and the width of the martensite needles is generally lower for the highest translational speed (compare Fig. 9 (b) and (c)).
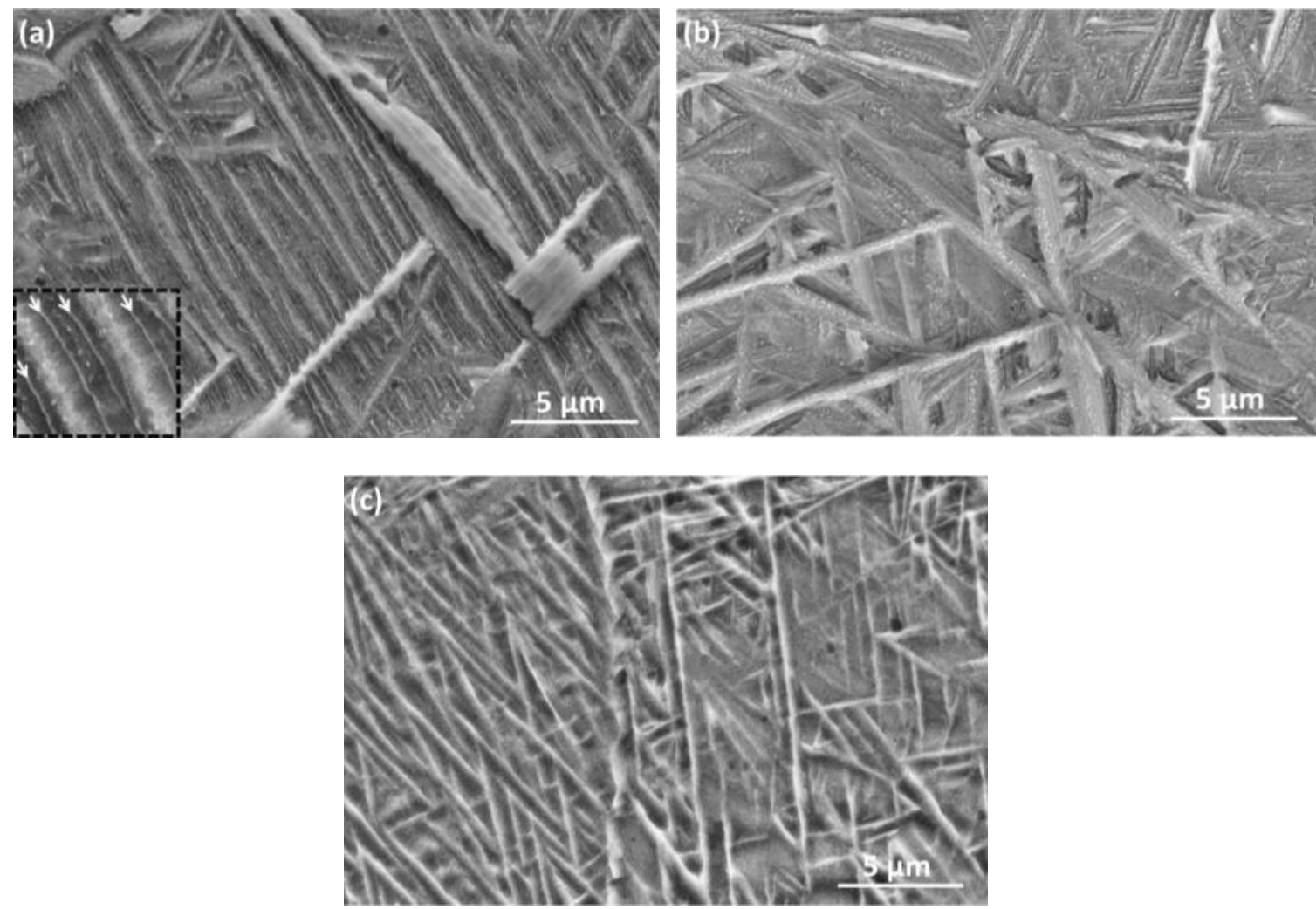

Fig. 9: $\alpha$ morphology of Ti-6Al-4V deposits generated at $v_{x}=8 m^{-1}$ (a), $v_{x}=16 m^{-1}$ (b) and $\mathrm{v}_{\mathrm{x}}=24 \mathrm{mms}^{-1}(\mathrm{c})$.

The previously mentioned equiaxed $\alpha_{\mathrm{p}}$ grains were found in all coatings and for all employed process parameters. They are located mainly close to the surface of the deposited material (Fig. 10 (a)), but are also present in the interior, where they are oriented in bands parallel to the coating/substrate interface and often located at prior $\beta$ GBs (Fig. 10 (a, b), Fig. 8 (c)). 
Particularly close to the surface and in coatings deposited at the lowest translational speed, the $\alpha_{w}$ lamellae in the vicinity of $\alpha_{p}$ are short and tend towards a blocky shape (Fig. 10 (b)).
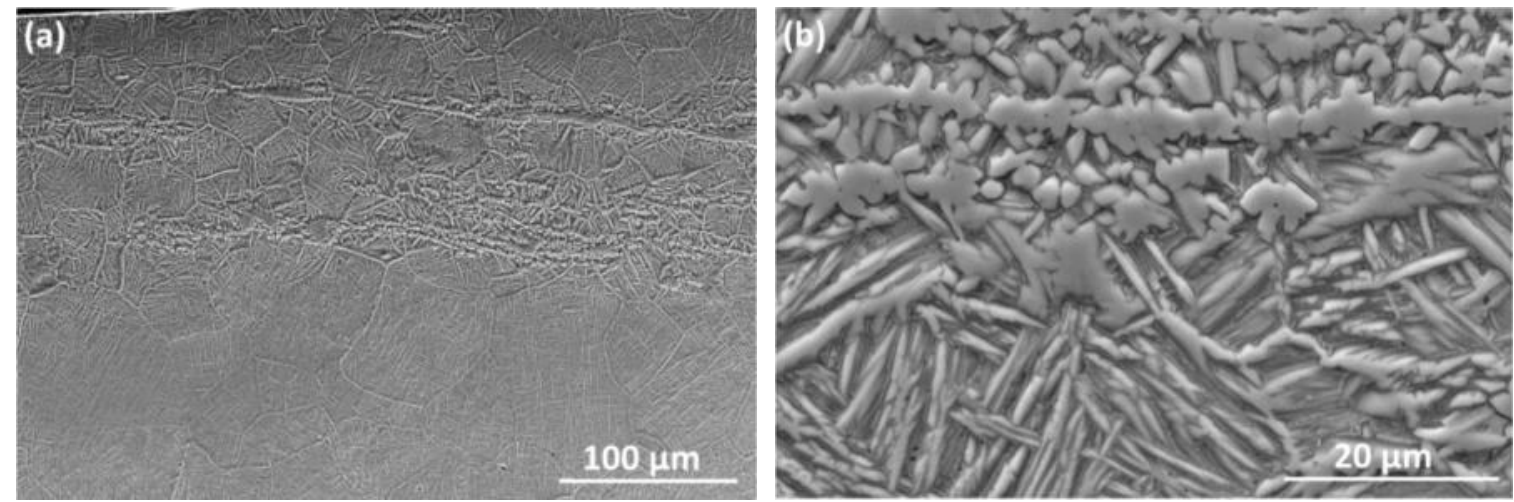

Fig. 10: Microstructure of Ti-6Al-4V deposits showing equiaxed grains close to the deposit surface for $\mathrm{v}_{\mathrm{x}}=16 \mathrm{mms}^{-1}$ (a) and $\mathrm{v}_{\mathrm{x}}=8 \mathrm{mms}^{-1}$ (b).

Measurements of chemical composition of $\alpha_{p}$ grains, and for comparison of adjacent regions of Widmannstätten or martensite $\alpha$ as depicted in Fig. 11 (a), were conducted by EDS on three different cross sections. Considering the quantitative uncertainty inherent to this method, the average values given in Fig. 11 (b) still show that $\alpha_{p}$ has an average Vanadium content of 1.7 wt $\%$, which is significantly lower than in the lamellar or acicular $\alpha$ regions.

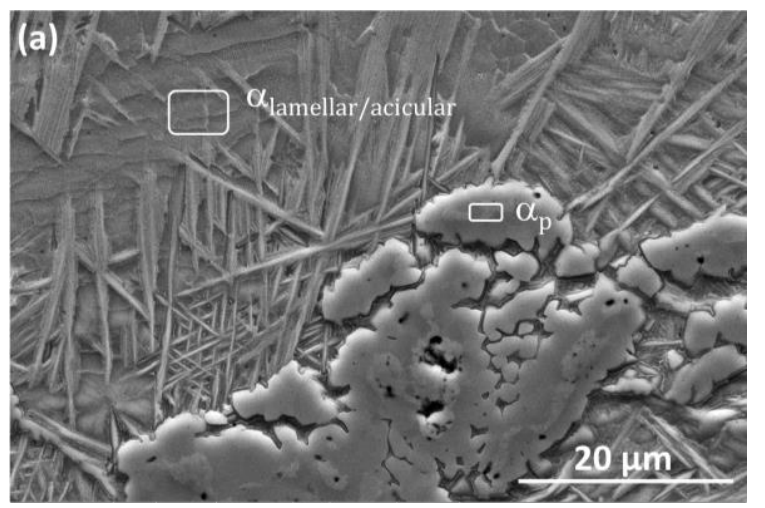

(b)

\begin{tabular}{l|ccc}
\hline $\mathrm{wt} \%$ & $\mathrm{Al}$ & $\mathrm{V}$ & $\mathrm{Ti}$ \\
\hline$\alpha_{\mathrm{p}}$ & $6.2 \pm 0.3$ & $1.7 \pm 0.3$ & $92.0 \pm 0.4$ \\
\hline$\alpha_{\text {lamellar }}$ & $7.0 \pm 0.4$ & $3.5 \pm 0.6$ & $89.5 \pm 0.7$ \\
\hline
\end{tabular}

Fig. 11: SEM image with $\alpha_{\mathrm{p}}$ and lamellar $\alpha$ regions denoting exemplary scan areas for EDS analysis (a) and results of eight EDS measurements on three different samples (b). 


\subsection{In-situ Experiment}

\subsubsection{Diffraction Results}

In Fig. 12 a single image of Debye-Scherrer rings recorded during the on-going process (stage 1) and the corresponding calculated diffraction pattern are presented. The $\mathrm{Cu}$ backing plate causes peaks of high intensity. The Ti phases identified are hexagonally close packed (hcp) $\alpha-$ Ti and body-centred cubic (bcc) $\beta$-Ti. No orthorhombic martensite ( $\alpha$ ") or other phases with different crystallographic structures were detected The lattice parameters determined after coating deposition and cooling to room temperature are presented in Tab. 4. It must be considered that the values give an average over the gauge volume including coating and substrate. Only relative changes in the lattice parameters are evaluated in the following sections. Several rings in Fig. 12 (a) show a slight variation of intensity along their circumference, indicating some degree of texture. This is most pronounced in the $\mathrm{Cu}$ rings, but also visible e.g. in the $\beta$ (200)-Ti ring. This light texture was neglected in the following phase content analysis (section 3.4.3), with respect to the large and inhomogeneous gauge volume in the experimental approach at this point.

(a)

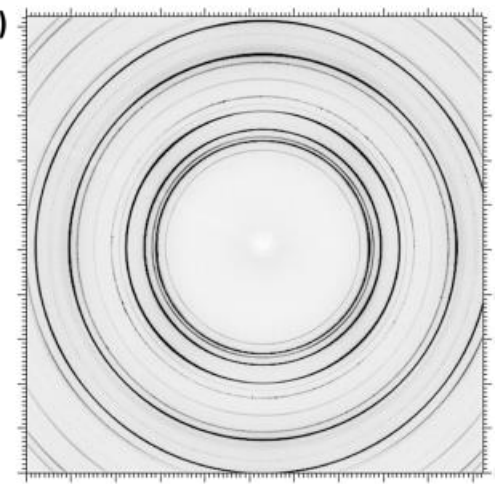

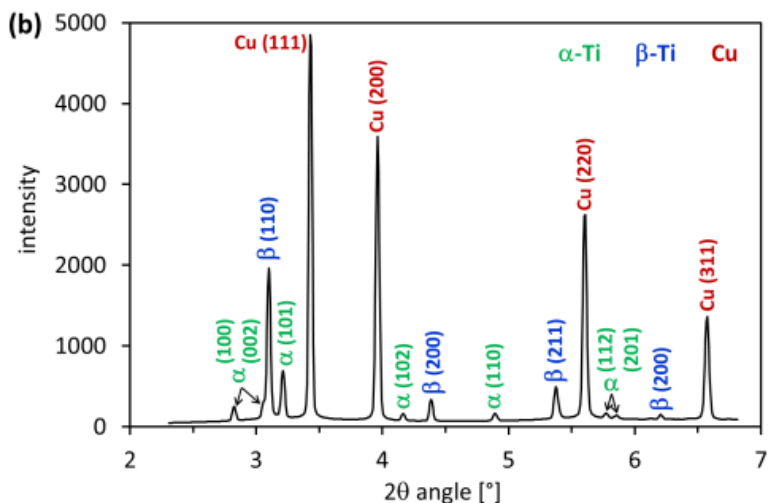

Fig. 12: Debye-Scherrer rings recorded $17.5 \mathrm{~mm}$ behind the stud during deposition $\left(\mathrm{v}_{\mathrm{x}}=16 \mathrm{mms}^{-1}\right)(\mathrm{a})$ and corresponding integrated diffraction data intensity vs. $2 \theta$ angle (b).

\begin{tabular}{l|ccc}
\hline transl. & lattice parameters of coated sheets at room temperature \\
speed & $\mathrm{a}(\alpha)$ & $\mathrm{c}(\alpha)$ & $\mathrm{a}(\beta)$ \\
\hline
\end{tabular}




\begin{tabular}{l|lll}
\hline $8 \mathrm{mms}^{-1}$ & $2.934 \AA$ & $4.684 \AA$ & $3.242 \AA$ \\
\cline { 2 - 4 } $16 \mathrm{mms}^{-1}$ & $2.936 \AA$ & $4.686 \AA$ & $3.246 \AA$ \\
\cline { 2 - 4 } $24 \mathrm{mms}^{-1}$ & $2.930 \AA$ & $4.680 \AA$ & $3.235 \AA$ \\
\hline
\end{tabular}

Tab. 4: Average lattice parameters determined after cooling at room temperature within the gauge volume (coating \& substrate).

The stacked diffraction patterns from $360^{\circ}$ integration from the same process run are shown in Fig. 13 (a) with the intensity coded in grey scale values. They give a qualitative overview over the changes throughout $20 \mathrm{~s}$ of measurement time. The horizontal line at $\mathrm{t}=0 \mathrm{~s}$ marks the transition from stage 1 (running process, varying material volume) to stage 2 (process stopped, fixed material volume). The diffraction pattern in Fig. 12 was recorded at $-1.8 \mathrm{~s}$. As can be seen in the detail in Fig. 13 (b), some intensity peaks are shifted towards larger angles when the process is stopped. Since from this moment on the gauge volume is fixed, the fast decrease in temperature in the deposited material becomes visible. The $\mathrm{Cu}$ sheet cools down quickly, leading to a large and quick shift of the peaks. The high-temperature $\beta$-Ti phase, which predominantly makes up the microstructure during the FS process, shows a similar evolution. The $\alpha$-Ti phase shows only a small shift, because during the initial fast cooling its fraction in the microstructure is low. In stage 1 the gauge volume is constantly at a temperature in the range of $840^{\circ} \mathrm{C}$ (for $\mathrm{v}_{\mathrm{x}}=16 \mathrm{mms}^{-1}$; measured in the coating/substrate interface) and the intensities are constant. After the process is stopped, the change in the intensity of $\alpha$-Ti and $\beta$-Ti peaks corresponds to the change in the volume fraction of the two phases during cooling, while the $\mathrm{Cu}$ peak intensity remains constant. At $\mathrm{t}=8 \mathrm{~s}$, the coated sheet has cooled down to approximately $270^{\circ} \mathrm{C}$, according to the thermocouple measurement shown in Fig. 5 . 

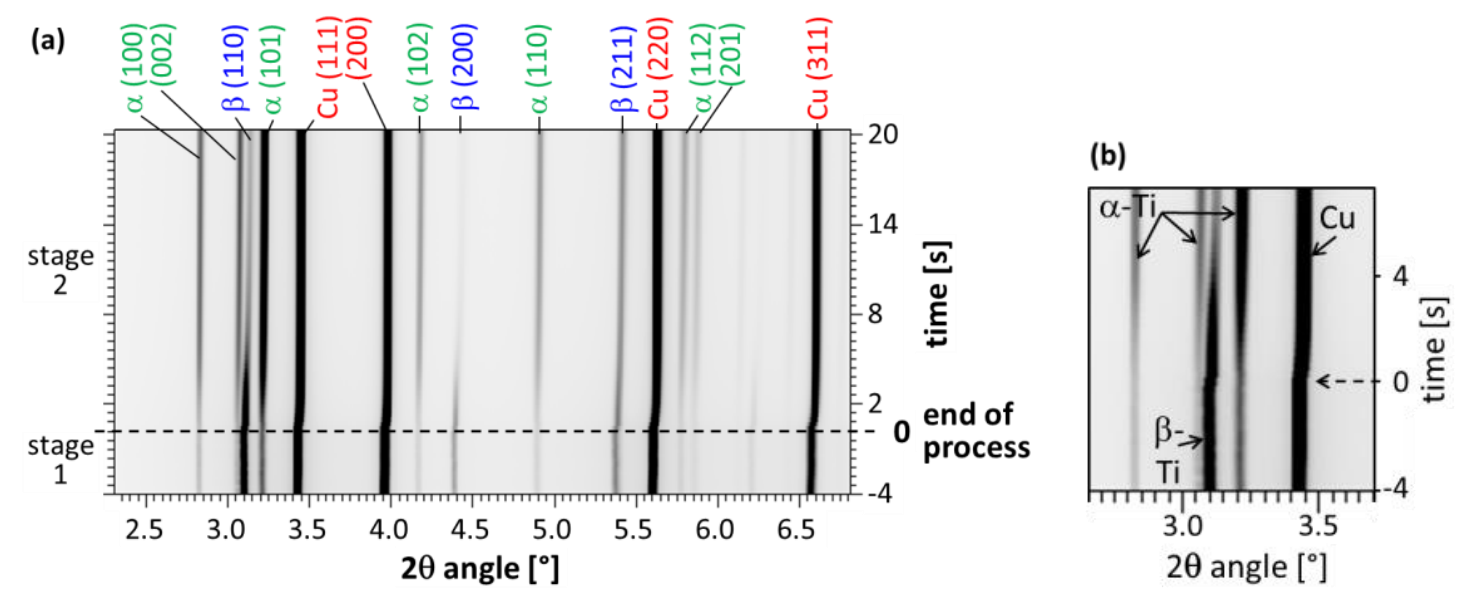

Fig. 13: Intensity vs. $2 \theta$ angle over $20 \mathrm{~s}$ measurement time $\left(v_{\mathrm{x}}=16 \mathrm{mms}^{-1}\right)$ (a) and detail showing the first five reflections (b). The horizontal line and the dashed arrow indicate the point in time when the deposition process was finished.

\subsection{2 $\beta$ Grain Growth}

In Fig. 14 a detail of a diffraction ring pattern obtained $1.5 \mathrm{~s}$ into stage 2 (i.e. $3.7 \mathrm{~s}$ after deposition) for a coating generated at $v_{x}=8 \mathrm{mms}^{-1}$ is presented. The high intensity spots on the $\beta$ (200) and $\beta$ (211) rings originate from single large grains, while the homogeneous intensity distribution on the other rings originates from a large number of small grains. Throughout the measurement time, all diffraction rings of the $\alpha$-phase are homogeneous; thus, no large $\alpha$ grains are present at any time (compare also microstructure in Fig. 8 to Fig. 10).

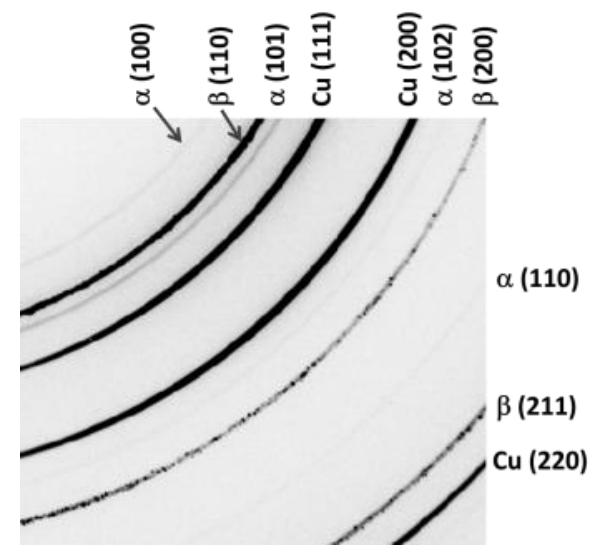

Fig. 14: Detail of diffraction pattern in stage 2, $3.7 \mathrm{~s}$ after deposition $\left(\mathrm{v}_{\mathrm{x}}=8 \mathrm{mms}^{-1}\right)$. 
A section of the $\beta$-Ti (200) diffraction ring, transformed into orthogonal coordinates for an azimuth range of $270^{\circ}$ to $360^{\circ}$, is presented as a function of time in Fig. 15 for $\mathrm{v}_{\mathrm{x}}=8 \mathrm{mms}^{-1}$ and $\mathrm{v}_{\mathrm{x}}=16 \mathrm{mms}^{-1}$. While the process is still on-going (stage $1, \mathrm{t} \leq 0 \mathrm{~s}$ ) a varying spotted appearance of the $\beta$-Ti ring is recognizable in both deposition runs. In stage 2 , when the movement of the sheet is stopped, the same grains remain within the gauge volume. From here on any further change in the intensity distribution on the ring must be due to growth or shrinkage of grains.

For $\mathrm{v}_{\mathrm{x}}=8 \mathrm{mms}^{-1}$ (Fig. 15 (a)) only insignificant changes can be seen after the first measurement frame in stage 2, $2.2 \mathrm{~s}$ after deposition. It can be concluded that the grain structure has formed during stage 1 and no significant grain growth takes place in stage 2 . The larger density of spots on the $\beta$-Ti ring of the deposition generated at $\mathrm{v}_{\mathrm{x}}=8 \mathrm{mms}^{-1}$ is related to its significantly higher coating thickness (compare Fig. 4).

For $\mathrm{v}_{\mathrm{x}}=16 \mathrm{mms}^{-1}$ the appearance of new spots indicating grain growth approximately $1 \mathrm{~s}$ into stage 2 (i.e. $2.1 \mathrm{~s}$ after deposition) is recognizable, as marked by the dashed circle in Fig. 15 (b). Other high intensity spots which were already present at $t=0 \mathrm{~s}$ do not show significant changes before they start to diminish.

The $\beta$-Ti ring has visibly started to fade, indicating the material's transformation to $\alpha-\mathrm{Ti}, 3 \mathrm{~s}$ after process stop (i.e. $4.1 \mathrm{~s}$ after deposition) for $\mathrm{v}_{\mathrm{x}}=16 \mathrm{mms}^{-1}$ (Fig. 15 (b)) and $7.5 \mathrm{~s}$ after process stop (i.e. $9.7 \mathrm{~s}$ after deposition) for $\mathrm{v}_{\mathrm{x}}=8 \mathrm{mms}^{-1}$ (Fig. 15 (a)). 

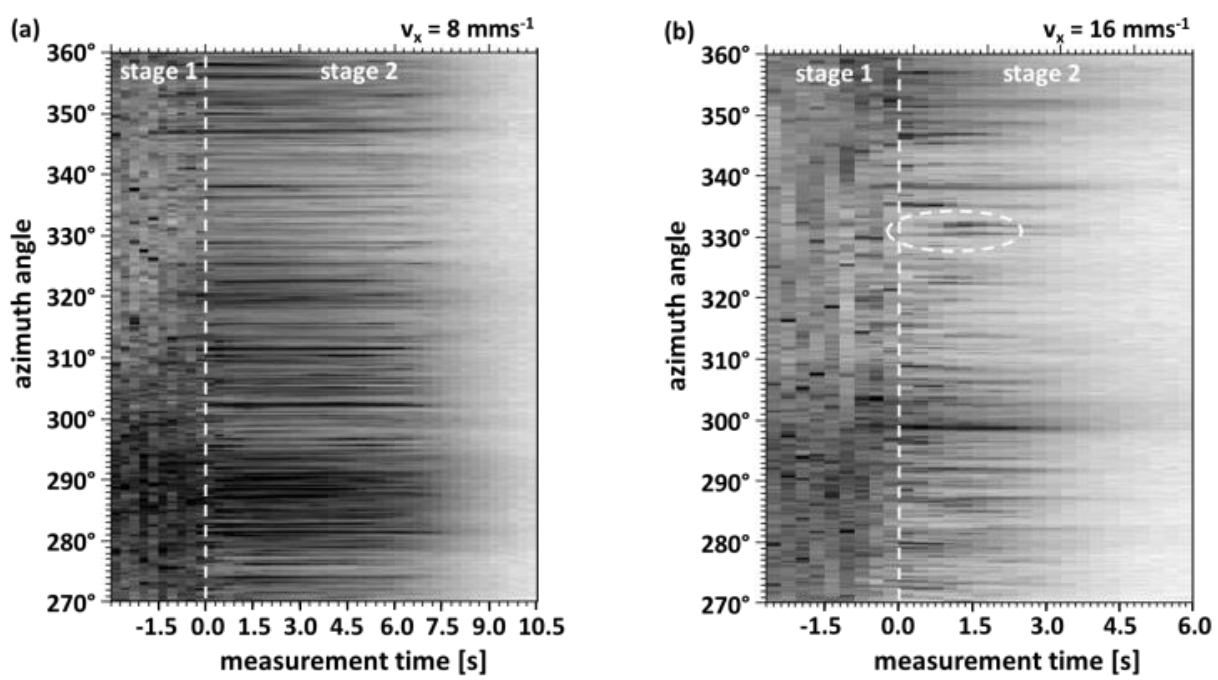

Fig. 15: Section of the $\beta$-Ti (200) diffraction ring, transformed into orthogonal coordinates for an azimuth range of $270^{\circ}$ to $360^{\circ}$, as a function of time in depositions generated at $\mathrm{v}_{\mathrm{x}}=8 \mathrm{mms}^{-}$ ${ }^{1}$ (a) and at $\mathrm{v}_{\mathrm{x}}=16 \mathrm{mms}^{-1}(\mathrm{~b})$.

\subsubsection{Phase Transformation}

The volume fraction of $\alpha$ and $\beta$ phase of each frame is plotted over measurement time in Fig. 16. The first values (stage $1, \mathrm{t} \leq 0 \mathrm{~s}$ ) were determined at the distance of $17.5 \mathrm{~mm}$ behind the stud during the running process. At this measurement position the coatings have already cooled down to some extent (compare Fig. 5 and Fig. 6). The $\beta$ phase fraction decreases from $82 \%$ to $63 \%$ to $55 \%$ with the translational speed increasing from $8 \mathrm{mms}^{-1}$ to $16 \mathrm{mms}^{-1}$ to $24 \mathrm{mms}^{-1}$.

Following the process stop at $t=0 \mathrm{~s}$ the values represent the phase fractions within a fixed material volume during cooling and the phase changes with decreasing temperature can be observed. At $\mathrm{t}=10 \mathrm{~s}$, temperatures are given estimated from thermocouple measurements presented in Fig. 5. The fact that the measured temperature at this point is slightly higher for $24 \mathrm{mms}^{-1}$ than for $16 \mathrm{mms}^{-1}$ translational speed is due to scatter and measurement inaccuracy inherent to the thermocouple method. For 16 and $24 \mathrm{mms}^{-1}$ translational speed (Fig. 16 (b) and (c)) a quick, continuous transformation from $\beta$ to $\alpha$ occurs, reaching final values of $94 \%$ and $96 \%$ of $\alpha$. Since this data was obtained in transmission, it provides an average through the cross section of deposited coating and substrate. From the images in Fig. 4 it can be seen that the 
heat-affected zone in the substrate has different dimensions for different deposition parameters and while it also - at least partially - transforms to $\beta$ during the process, part of the sheet material will remain in its original state with regard to phase composition.

The deposition generated at $8 \mathrm{mms}^{-1}$ translational speed shows a more complex behaviour of the phase transformations. After the process has stopped, the fraction of $\beta$ phase initially increases from 82 to $91 \%$. This behaviour was found for all deposition runs creating a large amount of deposited material, i.e. thick coating layers. The following $\beta \rightarrow \alpha$ phase transformation occurs significantly slower than for the other two parameters; however, the final $\alpha$ phase volume fraction of $94 \%$ is similar.

The rates of $\beta \rightarrow \alpha$ phase transformation (i.e. the evolution of the slope of the $\alpha$-curves in Fig. 16) for the three depositions shown in Fig. 16 are presented in Fig. 17. The maximum rate exists at the second measurement frame after process stop for $24 \mathrm{mms}^{-1}$ and $16 \mathrm{mms}^{-1}$ translational speed, ranging at $71 \% / \mathrm{s}$ and $46 \% / \mathrm{s}$, respectively. After these peak values, the transformation rate decreases quickly. For $16 \mathrm{mms}^{-1}$, a plateau is recognizable between 1 and $2 \mathrm{~s}$ ranging around $16 \% / \mathrm{s}$ transformation rate, marked by an arrow in Fig. 17. For the low translational speed of $8 \mathrm{mms}^{-1}$, the kinetics of phase transformation follows a different scheme. The initial $\alpha \rightarrow \beta$ transformation directly after the process stop results in negative values up to $t=2 \mathrm{~s}$ in Fig. 17. From here on, the transformation rate increases until a maximum value of $17 \% / \mathrm{s}$ is reached $8 \mathrm{~s}$ after process stop. This maximum is not a sharp peak as for the other process parameters, but decreases continuously during the following measurement time. It is interesting to note that the maximum transformation rate for the low translational speed is approximately the same as the plateau value observed for $\mathrm{v}_{\mathrm{x}}=16 \mathrm{mms}^{-1}$. The transformation rates drop below a value of $1 \% / \mathrm{s}$ at $3 \mathrm{~s}$ after process stop for $24 \mathrm{mms}^{-1}$, at $5 \mathrm{~s}$ for $16 \mathrm{mms}^{-1}$ and at $13 \mathrm{~s}$ (with few fluctuations) for $8 \mathrm{mms}^{-1}$. The completion of the transformation $(<0.05 \% / \mathrm{s})$ is reached at $6.3 \mathrm{~s}$ for $24 \mathrm{mms}^{-1}$, at $8.4 \mathrm{~s}$ for $16 \mathrm{mms}^{-1}$ and, except for the mentioned fluctuations, at $15 \mathrm{~s}$ for $8 \mathrm{mms}^{-}$ 
1. This corresponds to a time after deposition of $7 \mathrm{~s}, 9.5 \mathrm{~s}$ and $17.2 \mathrm{~s}$ for the three process parameters, respectively.
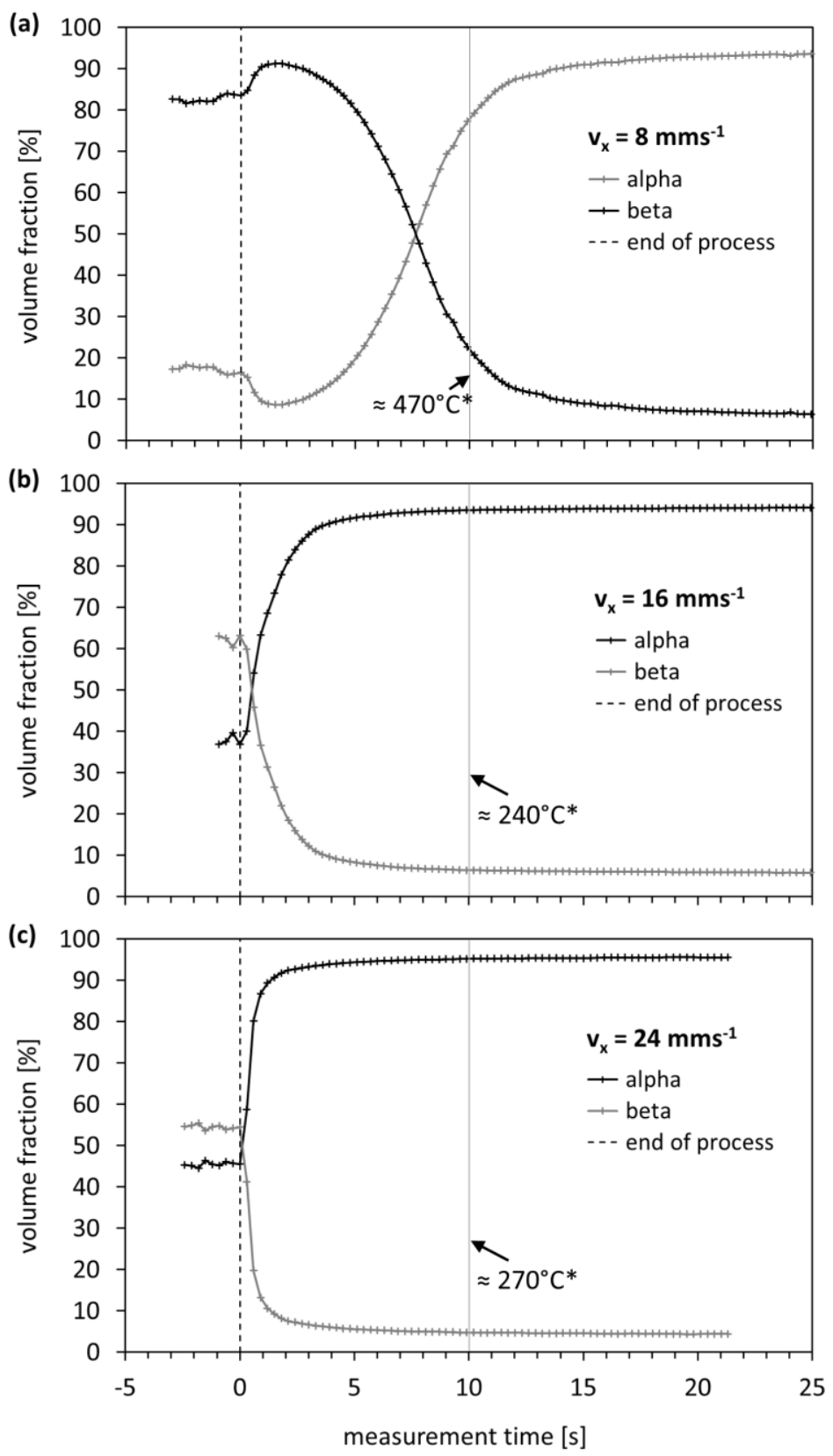

Fig. 16: Evolution of phase content in coated samples during cooling. $\mathrm{v}_{\mathrm{n}}=3000 \mathrm{~min}^{-1}$ and $\mathrm{v}_{\mathrm{x}}=8 \mathrm{mms}^{-1}(\mathrm{a}), \mathrm{v}_{\mathrm{x}}=16 \mathrm{mms}^{-1}(\mathrm{~b}), \mathrm{v}_{\mathrm{x}}=24 \mathrm{mms}^{-1}$ (c). 


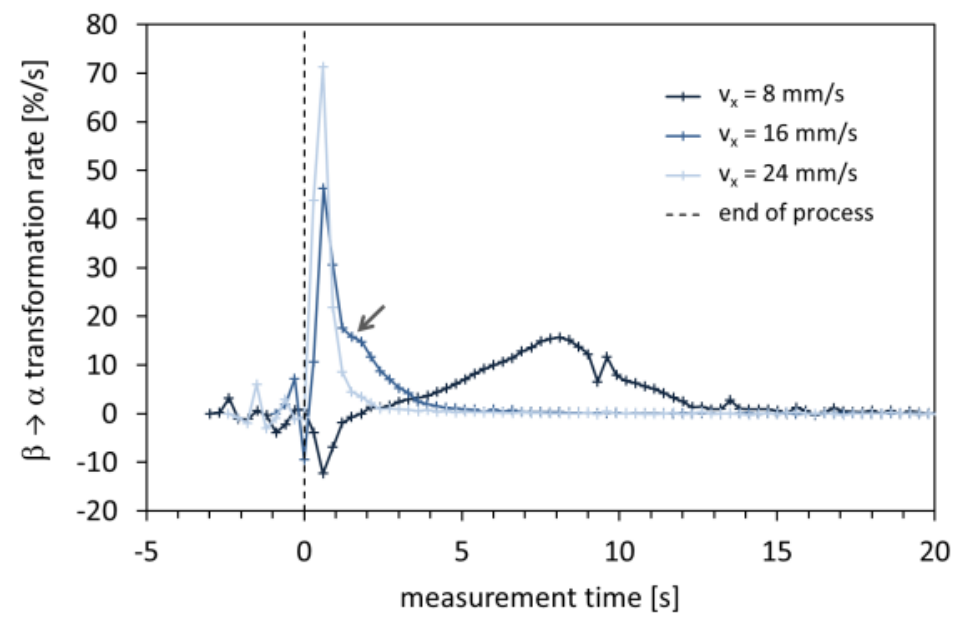

Fig. 17: Rate of phase transformation from $\beta$ to $\alpha$ in the three coated sheets presented in Fig. 16.

\section{Discussion}

\subsection{Influence of Translational Speed on FS Process and Temperature}

Within the investigated range of process parameters, a reduction of translational speed leads to the deposition of a larger volume of material. In FS plastified material is transferred from the stud tip to the substrate as a coating layer because it adheres to the moving substrate. At low translational speed the stud's dwell time on the substrate is longer and deposition takes place more slowly, with higher coating thickness. The plastic flow at high process temperatures of $\geq 1300^{\circ} \mathrm{C}$ results in dynamic recrystallization (DRX), which allows for the large deformation and provides a constant flow stress [21].

The temperature measurements presented in section 3.2 show significant differences between the thermocouple and the IR camera method. The two methods observe the temperatures in two different locations, the thermocouples in the interface to the substrate, and the IR camera on the top surface of the deposited material and the process zone. Here, the highest temperatures are measured. This is reasonable, since the heat source in FS is internal friction during the plastic deformation within the process zone [13]. The peak temperatures in the deposit/substrate 
interface were measured to be up to $300 \mathrm{~K}$ lower (for $\mathrm{v}_{\mathrm{x}}=24 \mathrm{mms}^{-1}$ ) due to fast heat conduction into the substrate and the $\mathrm{Cu}$ backing sheet.

The highest temperature and the lowest cooling rates are found for the low translational speed and the highest coating thickness $\left(\mathrm{v}_{\mathrm{x}}=8 \mathrm{mms}^{-1}\right)$. For this parameter, the heat input is high due to the longer dwell time and process duration. Additionally, the large amount of hot material deposited also has a "heat source" function. After coating deposition the substrate sheet is heated by conduction, while the coating cools down. This is also reflected by the HAZ which includes the full substrate thickness for the low translational speed.

\subsection{Phase Transformations and $\alpha$ Morphology}

\subsubsection{High-Temperature Phase Fractions and $\beta$ Grain Growth}

The volume fractions of $\alpha$ phase and temperatures recorded by thermocouples in stage 1 of the synchrotron measurements are $18 \%$ at $940^{\circ} \mathrm{C}, 37 \%$ at $840^{\circ} \mathrm{C}$ and $45 \%$ at $850^{\circ} \mathrm{C}$ for the translational speeds $8 \mathrm{mms}^{-1}, 16 \mathrm{mms}^{-1}$ and $24 \mathrm{mms}^{-1}$, respectively (Fig. 16). These phase volume fractions are mean values over the diffraction gauge volume, while the temperatures are those in the coating/substrate interface. Assuming the phase compositions were in equilibrium state, according to [24] the values would correspond to higher temperatures of $\approx$ $970^{\circ} \mathrm{C}(18 \%), \approx 950^{\circ} \mathrm{C}(37 \%)$ and $\approx 925^{\circ} \mathrm{C}(45 \%)$. This is coherent with the IR camera measurements which show that the surface temperature of the deposited material is significantly higher than in the interface. Thus, the $\beta$ phase fraction in the deposit is still high. The difference between measured and equilibrium phase fraction is smallest for $8 \mathrm{mms}^{-1}$, where the low translational speed leads to a more homogeneous temperature distribution in the process zone.

The $\beta$ grain size obtained from DRX for various rotational speeds during FS was analysed in [11], and was shown to increase significantly with the process temperature. In [25], a discrepancy between modelling and experimental determination of DRX grain size during hot compression of Ti-6Al-4V was assumed to be caused by pronounced grain growth following 
DRX. In the present experiments, the $\beta$ grain structure showed only small changes within approximately $2 \mathrm{~s}$ after deposition (Fig. 15). This implies that DRX grains form during FS, and their static growth during cooling is very limited. The time between deposition, i.e. the last introduction of plastic deformation, and the first diffraction measurements ranges between 0.7 and $2.2 \mathrm{~s}$ for the employed translational speeds. At this time the temperature has already dropped into the $\alpha / \beta$ regime and $\alpha$ formation may consume potentially stored energy, which may contribute to the prevention of $\beta$ grain growth [21] [26]. The current results therefore show that the prior $\beta$ grain size measured in the past ex-situ by metallographic methods corresponds closely to the actual DRX grain size during processing for the used Ti-6Al-4V alloy.

\subsubsection{Phase Evolution in the Substrate (HAZ)}

The initial increase of the $\beta$ phase fraction after process stop at $8 \mathrm{mms}^{-1}$ can be related to the phase transformation kinetics and the HAZ formation. For this translational speed the HAZ includes the complete substrate thickness, and it forms via heat conduction a few seconds after the material is deposited. According to the thermal cycle from the thermocouple in Fig. 5, at this translational speed the temperature was above $1000^{\circ} \mathrm{C}$ (i.e. in the $\beta$-regime), for approximately $3 \mathrm{~s}$. This corresponds with the duration of increasing $\beta$-phase fraction during cooling of $4.2 \mathrm{~s}$ after deposition ( $2 \mathrm{~s}$ after process stop, Fig. 17), taking into account some inaccuracy of the temperature measurements. The additional kink observed in the temperature curves of the low deposition speed welds at around $1100^{\circ} \mathrm{C}$ (Fig. 5) may be caused by the still ongoing $\alpha \rightarrow \beta$ transformation. The large gauge volume of these measurements in transition prevents a detailed analysis of the events in different depths of the coated sheets. For $\mathrm{v}_{\mathrm{x}}=16 \mathrm{mms}^{-1}$ the time above $1000^{\circ} \mathrm{C}$ was less than $1 \mathrm{~s}$, and for $\mathrm{v}_{\mathrm{x}}=24 \mathrm{mms}^{-1}$ the peak temperature on the substrate was below $1000^{\circ} \mathrm{C}$. Therefore, the $\beta$-phase increase in the substrate sheet was not detectable in the location of the X-ray measurements ( 0.7 and $1.1 \mathrm{~s}$ after deposition), although a change in $\alpha$ morphology indicative of a $\alpha \rightarrow \beta \rightarrow \alpha$ transformation was found in the HAZ even for $24 \mathrm{mms}^{-}$ 
${ }^{1}$ (Fig. 7 (b)). A comparable observation was made in [27] for in-situ measurements of phase transformations during gas tungsten arc welding of Ti-6Al-4V.

\subsubsection{Martensite Formation}

The $\beta \rightarrow \alpha$ transformation in Ti-6Al-4V can occur diffusionless forming hcp $\left(\alpha^{\prime}\right)$ or orthorhombic $\left(\alpha^{\prime \prime}\right)$ martensite, but the required cooling rates, as well as martensite start $\left(\mathrm{T}_{\mathrm{Ms}}\right)$ and finish $\left(\mathrm{T}_{\mathrm{Mf}}\right)$ temperatures reported in the literature are contradictory. While a fully martensitic microstructure was apparently found at a cooling rate of $5.1 \mathrm{Ks}^{-1}$ in [22] and at 18 $\mathrm{Ks}^{-1}$ in [23], the higher cooling rate of $410 \mathrm{Ks}^{-1}$ reported in [20] proved to be suitable for modelling phase transformations in [24]. Such discrepancies may be due to the alloy's high sensitivity to the concentration of interstitial elements, particularly oxygen [28] [29], but also to the fact that the different types of $\alpha$ are difficult to discern from each other [30]. They mostly assume a lamellar or acicular appearance and have an hcp crystallographic structure, except for $\alpha$ ". The main differences between the hcp phases are the local distribution of alloying elements [22] and variations mainly in the lattice parameter c [30]. Still, the different types of $\alpha$ phase have a significant influence on the (particularly cyclic) mechanical properties of the alloy and their differentiation is therefore of importance [26]. In [30] synchrotron radiation was utilized for phase analysis on the surface of Ti alloys at room and high temperature and $\alpha^{\prime}$ martensite was identified based on peak broadening. This approach was omitted in the current study because of the large, inhomogeneous gauge volume and the fact that thermal gradients also cause changes in peak width. Various temperature ranges for martensite formation have been reported for alloy Ti-6Al-4V. The values given in [23] are $\mathrm{T}_{\mathrm{Ms}}=860^{\circ} \mathrm{C}$ and $\mathrm{T}_{\mathrm{Mf}}=710^{\circ} \mathrm{C}$, while other publications state values in the range of $\mathrm{T}_{\mathrm{Ms}} \approx 600^{\circ} \mathrm{C}$ [24] [20]. During in-situ observations of phase transitions in gas tungsten arc welding, martensite transformation was found to occur within a temperature range of $\mathrm{T}_{\mathrm{Ms}}=650^{\circ} \mathrm{C}$ and $\mathrm{T}_{\mathrm{Mf}}=450^{\circ} \mathrm{C}$ [27]. 
In the coatings examined in this work cooling rates of $26 \mathrm{Ks}^{-1}\left(\mathrm{v}_{\mathrm{x}}=8 \mathrm{mms}^{-1}\right), 77 \mathrm{Ks}^{-1}$ $\left(v_{x}=16 \mathrm{mms}^{-1}\right)$ and $61 \mathrm{Ks}^{-1}\left(\mathrm{v}_{\mathrm{x}}=24 \mathrm{mms}^{-1}\right)$ have been recorded in the coating/substrate interface in the temperature range between $600^{\circ} \mathrm{C}$ and $400^{\circ} \mathrm{C}$. From the microstructure investigations by SEM it can be concluded that martensite formed for the two higher deposition speeds, but cooling rates were not sufficient to form a fully martensitic microstructure, in accordance with [20] [24] [27]. Further, no additional reflections from $\alpha$ " martensite were observed in the present X-ray study.

\subsubsection{Influence of Translational Speed on $\alpha$ Morphology}

In [11] TEM investigations revealed a mixed microstructure with both hcp $\alpha$ and hcp $\alpha^{\prime}$ martensite in Ti-6Al-4V FS coatings, which is confirmed by the findings in this work. For 16 and $24 \mathrm{mms}^{-1}$ translational speed, the microstructure is dominated by regions of $\alpha^{\prime}$ martensite and Widmannstätten $\alpha_{\mathrm{w}}$. On the contrary, in the deposit generated at $8 \mathrm{mms}^{-1} \alpha^{\prime}$ martensite was not visible in the SEM images, but instead colonies of $\alpha_{\mathrm{m}}$ typical for a massive transformation at low cooling rates [7] appeared. Only in these $\alpha_{\mathrm{m}}$ colonies $\beta$ platelets between the $\alpha$ lamellae were thick enough to be observed by SEM as well. In [31], after Friction Stir Processing of Ti$6 \mathrm{Al}-4 \mathrm{~V}$ which introduces similar deformation and thermal cycles, also a combination of $\alpha_{\mathrm{GB}}$ with $\alpha_{\mathrm{W}}$ and $\alpha^{\prime}$ was found. Such mixed and heterogeneous microstructures are regularly present in Ti-6Al-4V technical applications, due to the alloy's sensitivity to local temperature and cooling rate differences and its low thermal conductivity [32] [33].

The $\alpha$ morphologies in the different deposits can be clearly correlated with the differences in phase transformation rates. The two faster translational speeds show a rapid transformation within the first few seconds after deposition. At $\mathrm{v}_{\mathrm{x}}=24 \mathrm{mms}^{-1}$ a volume fraction of $90 \% \alpha$ is reached less than $2 \mathrm{~s}$ after deposition, and at $\mathrm{v}_{\mathrm{x}}=16 \mathrm{mms}^{-1}$ after 4 to $5 \mathrm{~s}$. The low translational speed of $8 \mathrm{mms}^{-1}$ shows more sluggish transformation, reaching $90 \%$ of $\alpha$ only approximately $16 \mathrm{~s}$ after deposition. Thus, there is no simple correlation between cooling or transformation 
rate and translational speed. The microstructure investigation implies that for the formation of $\alpha^{\prime}$ in the two faster welds the high initial peak transformation rates of $71 \% / \mathrm{s}$ and $46 \% / \mathrm{s}$ are required. The peak transformation rate of the $8 \mathrm{mms}^{-1}$ deposition of $16 \% / \mathrm{s}$, which is also found as a plateau value in the $16 \mathrm{mms}^{-1}$ deposition, may be characteristic for $\alpha_{\mathrm{W}}$ formation. The higher cooling rates were observed to lead to thinner $\alpha_{\mathrm{W}}$ and $\alpha_{\mathrm{m}}$ lamellae, which is expected due to shorter diffusion distances [21] [22].

Frequently the proposition is made to tailor the microstructure in FS coatings by selecting adequate process parameters. The present results show that the "heat source function" of the deposited hot material (depending on coating thickness and width) is an important factor with regard to microstructure evolution. The coating dimensions depend on the process parameters, in particular the rotational and translational speeds as well as the axial force or feed rate. This dependence must be known, as well as the heat flow or cooling conditions, before the microstructure control based on process parameters in FS of Ti-6Al-4V is feasible.

\subsubsection{Globular $\alpha$ Grains}

The presence of the small equiaxed $\alpha_{\mathrm{p}}$ grains is an anomaly in Ti-6Al-4V $\beta$-processed at $1300^{\circ} \mathrm{C}$. Upon cooling from the $\beta$ state, $\alpha$ generally forms in lamellar or acicular shape. To obtain equiaxed $\alpha$ grains, processing would need to take place in the $\alpha+\beta$ regime, forming recrystallized equiaxed $\alpha$ through shearing of the previously existing lamellae (typically denominated $\alpha_{p}$, since they are the primary $\alpha$ grains upon cooling) [26] [34]. Another possibility to form equiaxed $\alpha$ is annealing of a lamellar microstructure at around $800^{\circ} \mathrm{C}$, leading to globularization via diffusion and grain boundary migration [7] [35]. At low cooling rates after annealing or processing in the $\beta$ regime, thick $\alpha$ lamellae form [21] [22]. At very slow cooling they can assume a blocky and close to equiaxed appearance [7]. Equiaxed grains have further been reportedly found within adiabatic shear bands during high-speed deformation at room 
temperature (grain size $0.1 \mu \mathrm{m}$ ) [36] and deformation bands [21], and in both cases are explained by DRX under locally increased temperature.

In the present investigations the equiaxed $\alpha_{\mathrm{p}}$ grains are found frequently close to the coating surface, implying that they are related to an increased oxygen content. They have a low content of alloying elements, in particular the $\beta$-stabilizer $\mathrm{V}$, therefore diffusion processes towards the equilibrium state must have occurred [18]. Oxygen cannot be detected reliably by EDS and small changes to the lattice parameters caused by interstitial oxygen could not be determined from the X-ray measurements, due to the large gauge volume and the small amount of $\alpha_{\mathrm{p}}$. No protective gas was used, and the intake of oxygen at the high processing temperatures is very probable. In [37] surface layers of similar appearance were found during thermal cycling of titanium alloy VT3-1. The dissolved oxygen caused $\beta \rightarrow \alpha$ transformation at high temperatures leading to the formation of an $\alpha$ layer on the surface. The blocky appearance of the $\alpha$ phase in the vicinity of $\alpha_{p}$ may be due to further oxygen diffusion during cooling, which changes the $\beta \rightarrow \alpha$ transformation kinetics and therefore the shape of obtained $\alpha$ [37] [28]. Bands of $\alpha_{\mathrm{p}}$ were also found in the deposit interior, parallel to the substrate surface and therefore the main shear direction. Material which at some stage of processing was on the surface in contact to air passed into the interior of the deposit under the intensive shear flow. These bands of $\alpha_{\mathrm{p}}$ may play a relevant role in technical applications of the FS coatings, since Oxygen enriched Ti-6Al-4V tends to be brittle and may display deteriorated mechanical properties [38].

\section{Conclusions}

From the in-situ FS experiments supported by electron microscopy and temperature measurements, the following conclusions can be drawn:

1. The diffraction measurements in transmission do not allow an analysis of the various events in different depths of the coated sheets. A detailed investigation of phases with small volume 
fractions (e.g. $\alpha_{\mathrm{p}}$ ) or small differences in lattice parameters is also hindered. Nevertheless, useful information on grain growth and phase transformation behaviour can be gained.

2. The amount of hot material deposited (i.e. coating thickness and width) has a significant influence on the cooling and phase transformation rates, since it acts as a heat source. The dependence of coating dimensions on process parameters must be known in order to control the resulting microstructure.

3. Very limited static $\beta$ grain growth occurs within $2 \mathrm{~s}$ after deposition only. The high temperature DRX grain size is the determining factor for the $\beta$ grain size.

4. Martensite $\alpha^{\prime}$ formed at the two higher deposition speeds at peak $\beta \rightarrow \alpha$ transformation rates of $71 \% / \mathrm{s}$ and $46 \% / \mathrm{s}$, but cooling rates were not sufficient to form a fully martensitic microstructure. The peak transformation rate of the lowest translational speed of $16 \% / \mathrm{s} \mathrm{did} \mathrm{not}$ lead to martensite formation. The microstructure of all depositions is dominated by Widmannstätten $\alpha_{\mathrm{W}}$ and grain boundary $\alpha_{\mathrm{GB}}$.

5. Phase transformations were completed within 7 to $17 \mathrm{~s}$ after deposition. This information can only be gained from in-situ measurements, and together with the cooling rates is of interest e.g. for the prediction of residual stresses.

\section{Acknowledgements}

The authors thank Menno Peters (HZG), Henry Loitz and Nils Clausing (H. Loitz - Robotik, Hamburg, Germany) for their exceptional efforts in the set-up, transport and operation of the welding equipment. We thank Natalia Lopes do Vale (Universidade Federal de Pernambuco, Brazil) and Tobias Bucken (University of Duisburg-Essen, Germany) for their support with measurements and metallographic analyses. Financial support by the Assessment, Computing and Engineering Centre (ACE) is gratefully acknowledged. Finally, the authors wish to express their gratitude to Prof. Norbert Huber (HZG) for his encouragement and support. 


\section{$7 \quad$ References}

[1] B.M. Jenkins, E.D. Doyle, Hardfacing by low-pressure friction surfacing, Transactions of the Institution of Engineers, Australia: Mechanical Engineering 14/3 (1989) 178-185.

[2] A.W. Batchelor, S. Jana, C.P. Koh, C.S. Tan, The effect of metal type and multi-layering on friction surfacing, Journal of Materials Processing Technology 57 (1996) 172-182.

[3] T. Shinoda, J.Q. Li, Y. Katoh, T. Yashiro, Effect of process parameters during friction coating on properties of non-dilution coating layers, Surface Engineering 14/3 (1998) 211-216.

[4] H. Krohn, S. Hanke, M. Beyer, J. dos Santos, Influence of external cooling configuration on friction surfacing of AA6082 T6 over AA2024 T351, Manufacturing Letters 5 (2015) $17-20$.

[5] G.M. Bedford, Friction surfacing for wear applications, Metals and Materials 6/11 (1990) 702-705.

[6] J. Li, T. Shinoda, Eigenschaften reibauftraggeschweißter Schneidenkanten, Schweissen \& Schneiden 52/5 (2000) 278-281.

[7] G. Lütjering, J.C. Williams, A. Gysler, Microstructure and mechanical properties of titanium alloys. In: Microstructure and Properties of Materials, World Scientific Publishing Co Pte Ltd (2000) pp. 1-77.

[8] V. Fitseva, H. Krohn, S. Hanke, J.F. dos Santos, Friction surfacing of Ti-6Al-4V: Process characteristics and deposition behaviour at various rotational speeds, Surface and Coatings Technology 278 (2015) 56-63.

[9] S. Hanke, M. Beyer, A. Silvonen, J.F. dos Santos, A. Fischer, Cavitation erosion of Cr60Ni40 coatings generated by friction surfacing, Wear 301/1-2 (2013) 415-423.

[10] J.J.S. Dilip, G.D. Janaki Ram, Friction Freeform Fabrication of Superalloy Inconel 718: Prospects and Problems, Metallurgical and Materials Transactions B 45B (2014) 182192.

[11] V. Fitseva, S. Hanke, J.F. dos Santos, P. Stemmer, B. Gleising, The role of process temperature and rotational speed in the microstructure evolution of Ti-6Al-4V friction surfacing coatings, Materials and Design 110 (2016) 112-123.

[12] S. Hanke, M. Beyer, J. dos Santos, A. Fischer, Friction Surfacing of a Cold Work Tool Steel - Microstructure and Sliding Wear Behaviour, Wear 308/1-2 (2013) 180-185.

[13] S. Hanke, J.F. dos Santos, Comparative study of severe plastic deformation at elevated temperatures of two Aluminium alloys during Friction Surfacing, Journal of Materials Processing Technology 247 (2017) 257-267.

[14] K. Fukakusa, On the characteristics of the rotational contact plane - A fundamental study of friction surfacing, Welding International 10/7 (1996) 524-529.

[15] H. Khalid Rafi, G. Phanikumar, K. Prasad Rao, Material flow visualization during Friction Surfacing, Metallurgical and Materials Transactions 42A (2011) 937-939. 
[16] A.P. Hammersley, S.O. Svensson, M. Hanfland, A.N. Fitch, D. Häusermann, Twodimensional detector software: From real detector to idealised image or two-theta scan, High Pressure Research 14 (1996) 235-248.

[17] H.R. Wenk, L. Lutterotti, S.C. Vogel, Rietveld texture analysis from TOF neutron diffraction data, Powder Diffraction 25/3 (2010) 283-296.

[18] L. Zeng, T.R. Bieler, Effects of working, heat treatment, and aging on microstructural evolution and crystallographic texture of $\alpha, \alpha^{\prime}, \alpha^{\prime \prime}$ and $\beta$ phases in Ti-6Al-4V wire, Materials Science and Engineering A392 (2005) 403-414.

[19] J.W. Elmer, T.A. Palmer, S.S. Babu, E.D. Specht, In situ observations of lattice expansion and transformation rates of $\mathrm{a}$ and $\mathrm{b}$ phases in Ti-6Al-4V, Materials Science and Engineering A391 (2005) 104-113.

[20] T. Ahmed, H.J. Rack, Phase transformations during cooling in $\alpha+\beta$ titanium alloys, Materials Science and Engineering A243 (1998) 206-211.

[21] R. Ding, Z.X. Guo, A. Wilson, Microstructural evolution of a Ti-6Al-4V alloy during thermomechanical processing, Materials Science and Engineering A327 (2002) 233-245.

[22] F.J. Gil, M.P. Ginebra, J.M. Manero, J.A. Planell, Formation of $\alpha$-Widmannstätten structure: effects of grain size and cooling rate on the Widmannstätten morphologies and on the mechanical properties in Ti6Al4V alloy, Journal of Alloys and Compounds 329 (2001) 142-152.

[23] J. Sieniawski, W. Ziaja, K. Kubiak, M. Motyka, Microstructure and Mechanical Properties of High Strength Two-Phase Titanium Alloys, In: Titanium Alloys - Advances in Properties Control, IN TECH d.o.o, Croatia (2003) ISBN 978-953-51-1110-8, pages 69-80.

[24] C.C. Murgau, R. Pederson, L.E. Lindgren, A model for Ti-6Al-4V microstructure evolution for arbitrary temperature changes, Modelling and Simulation in Materials Science and Engineering 20 (2012) 055006.

[25] R. Ding, Z.X. Guo, Microstructural evolution of a Ti-6Al-4V alloy during b-phase processing: experimental and simulative investigations, Materials and Engineering A365 (2004) 172-179.

[26] G. Lütjering, Influence of processing on microstructure and mechanical properties of $(\alpha+\beta)$ titanium alloys, Materials Science and Engineering A243 (1998) 32-45.

[27] J.W. Elmer, T.A. Palmer, S.S. Babu, W. Zhang, T. DebRoy, Phase transformation dynamics during welding of Ti-6Al-4V, Journal of Applied Physics 95/12 (2004) 83278339.

[28] M. Cormier, F. Claisse, Beta-alpha phase transformation in Ti and Ti-O alloys, Journal of the Less-Common Metals 34 (1974) 181-189.

[29] S. Malinov, W. Sha, C.S. Voon, In situ high temperature microscopy study of the surface oxidation and phase transformations in titanium alloys, Journal of Microscopy 207/3 (2002) 163-168. 
[30] S. Malinov, W. Sha, Z. Guo, C.C. Tang, A.E. Long, Synchrotron X-ray diffraction study of the phase transformations in titanium alloys, Materials Characterization 48 (2002) 279295.

[31] B. Li, Y. Shen, W. Hu, L. Luo, Surface modification of Ti-6Al-4V alloy via friction-stir processing: Microstructure evolution and dry sliding wear performance, Surface \& Coatings Technology 239 (2014) 160-170.

[32] M.T. Jovanovic, S. Tadic, S. Zec, Z. Miskovic, I. Bobic, The effect of annealing temperatures and cooling rates on microstructure and mechanical properties of investment cast Ti-6Al-4V alloy, Materials and Design 27 (2006) 192-199.

[33] A.L. Pilchak, T.F. Broderick, Evidence of a massive transformation in a Ti-6Al-4V solidstate weld?, JOM / The Journal of The Minerals, Metals \& Materials Society 65/5 (2013) 636-642.

[34] S.L. Semiatin, V. Seetharaman, I. Weiss, Flow behaviour and globularization kinetics during hot working of Ti-6Al-4V with a colony alpha microstructure, Materials Science and Engineering A263 (1999) 257-271.

[35] I. Weiss, F.H. Froes, D. Eylon, G.E. Welsch, Modification of alpha morphology in Ti-6Al-4V by thermomechanical processing, Metallurgical Transactions 17A (1986) 1935-1947.

[36] B. Wang, J. Li, J. Sun, X. Luo, Z. Liu, H. Liu, Adiabatic shear bands in Ti-6Al-4V alloy with lamellar microstructure, Journal of Materials Engineering and Performance 23/5 (2014) 1896-1903.

[37] V. Sinka, L. Pesek, Growth and damage of the $\alpha$-stabilized layer in the titanium alloy VT3-1 during thermal cycling, Metallurgija 42/2 (2003) 91-93.

[38] Y. Cui, Q. Meng, B. Zhang, F. Yan, Fracture analysis of Ti-6Al-4V bolts, Engineering Failure Analysis 13 (2006) 669-672. 